\title{
In Vitro Effects of Low-Intensity Pulsed Ultrasound Stimulation on the Osteogenic Differentiation of Human Alveolar Bone-Derived Mesenchymal Stem Cells for Tooth Tissue Engineering
}

\author{
KiTaek Lim, ${ }^{1,2}$ Jangho Kim, ${ }^{1}$ Hoon Seonwoo, ${ }^{1}$ Soo Hyun Park, ${ }^{1}$ \\ Pill-Hoon Choung, ${ }^{2,3}$ and Jong Hoon Chung ${ }^{1,4}$ \\ ${ }^{1}$ Department of Biosystems \& Biomaterials Science and Engineering, Seoul National University, Seoul 151-921, Republic of Korea \\ ${ }^{2}$ Department of Oral and Maxillofacial Surgery and Dental Research Institute, School of Dentistry, Seoul National University, \\ Seoul, Republic of Korea \\ ${ }^{3}$ Tooth Bioengineering National Research Laboratory of Post BK21, School of Dentistry, Seoul National University, \\ Seoul, Republic of Korea \\ ${ }^{4}$ Research Institute for Agriculture and Life Sciences, Seoul National University, Seoul 151- 921, Republic of Korea
}

Correspondence should be addressed to Pill-Hoon Choung; choungph@snu.ac.kr and Jong Hoon Chung; jchung@snu.ac.kr

Received 4 May 2013; Revised 4 July 2013; Accepted 9 July 2013

Academic Editor: Aaron W. James

Copyright (C) 2013 KiTaek Lim et al. This is an open access article distributed under the Creative Commons Attribution License, which permits unrestricted use, distribution, and reproduction in any medium, provided the original work is properly cited.

\begin{abstract}
Ultrasound stimulation produces significant multifunctional effects that are directly relevant to alveolar bone formation, which is necessary for periodontal healing and regeneration. We focused to find out effects of specific duty cycles and the percentage of time that ultrasound is being generated over one on/off pulse period, under ultrasound stimulation. Low-intensity pulsed ultrasound ((LIPUS) $1 \mathrm{MHz}$ ) with duty cycles of $20 \%$ and $50 \%$ was used in this study, and human alveolar bone-derived mesenchymal stem cells (hABMSCs) were treated with an intensity of $50 \mathrm{~mW} / \mathrm{cm}^{2}$ and exposure time of $10 \mathrm{~min} /$ day. hABMSCs exposed at duty cycles of $20 \%$ and $50 \%$ had similar cell viability (O.D.), which was higher $\left({ }^{*} \mathrm{P}<0.05\right)$ than that of control cells. The alkaline phosphatase (ALP) was significantly enhanced at 1 week with LIPUS treatment in osteogenic cultures as compared to control. Gene expressions showed significantly higher expression levels of CD29, CD44, COL1, and OCN in the hABMSCs under LIPUS treatment when compared to control after two weeks of treatment. The effects were partially controlled by LIPUS treatment, indicating that modulation of osteogenesis in hABMSCs was related to the specific stimulation. Furthermore, mineralized nodule formation was markedly increased after LIPUS treatment than that seen in untreated cells. Through simple staining methods such as Alizarin red and von Kossa staining, calcium deposits generated their highest levels at about 3 weeks. These results suggest that LIPUS could enhance the cell viability and osteogenic differentiation of hABMSCs, and could be part of effective treatment methods for clinical applications.
\end{abstract}

\section{Introduction}

Many research studies have been conducted on cell proliferation and differentiation using ultrasound stimulators, as well as the development of therapeutic applications. In addition, commercially available clinical products using this technology have already been released. Ultrasound stimulation is acoustic energy at frequencies above the limit of human hearing. It is a form of mechanical energy that can be conducted into the body as high-frequency acoustical waves. The micromechanical strains produced by these pressure waves in body tissue can result in biochemical events at the cellular level [1-3].

In vitro studies have suggested that LIPUS treatment produces significant multifunctional effects that are directly relevant to bone formation and resorption. Clinical investigations involving LIPUS have shown successful healing of delayed unions and nonunions. LIPUS has been widely 
found to stimulate fracture healing in animal models and in clinical treatments $[4,5]$. LIPUS has also been reported to accelerate bone maturation in distraction osteogenesis cases in animal models $[6,7]$ and in clinical treatments $[8,9]$. LIPUS may induce a micromechanical stimulation of the bone and induce osteogenesis, according to Wolff's Law [10]. In particular, the differential absorption of LIPUS may establish a gradient of mechanical strain in the healing callus that stimulates periosteal bone formation [11, 12].

However, the exact use of ultrasound stimulators has been controversial due to side effects related to proper intensities or time, as well as other parameter choices such as duty cycle. Thus, we sought to provide further guidance to the use of LIPUS by evaluating the effects of duty cycles of $20 \%$ and $50 \%$ during $10 \mathrm{~min}$ per day. Our research team has already investigated and reported on the effects of LIPUS on proliferation and differentiation of hABMSCs across a range of intensities of ultrasonic power [13]. We ascertained that LIPUS treatment was effective in promoting the proliferation and osteogenic differentiation of hABMSCs.

However, these and other preliminary findings regarding LIPUS did not investigate the effects of changes in the duty cycle of the ultrasound stimulators. The role of the duty cycle is particularly important because of the method delivered to tissues during peak operation times. There are no previous studies investigating the effects of the low duty cycle condition of the LIPUS treatment on the cell growth and differentiation of hABMSCs. In addition, despite its pronounced effects during the osteogenesis process, the underlying mechanism of LIPUS remains unclear.

Thus, this study examines the effects of LIPUS treatments with differing pulsed duty cycles on in vitro cell growth and osteogenic differentiation of hABMSCs. The aim of this study was to investigate the effects of LIPUS (with duty cycles of $20 \%$ and $50 \%$ ) on proliferation and differentiation of hABMSCs for tooth tissue engineering.

\section{Materials and Methods}

2.1. Cell Culture. hABMSCs were taken from the Intellectual Biointerface Engineering Center, Dental Research Institute, College of Dentistry, and Seoul National University. The cells were cultured in alpha-minimum essential medium $((\alpha-$ MEM) Welgene Inc., Korea) supplemented with 10\% fetal bovine serum ((FBS) Welgene Inc., Korea), 10 mM L-ascorbic acids (Sigma, USA), and antibiotics $(10,000 \mathrm{U} / \mathrm{mL}$ penicillin, $10 \mathrm{mg} / \mathrm{mL}$ streptomycin, and $25 \mathrm{ug} / \mathrm{mL}$ amphotericin B). hABMSCs were placed in $100 \mathrm{~mm}$ culture dishes at a density of $3.0 \times 10^{4}$ cells $/ \mathrm{cm}^{2}$. Cells were maintained in a humidified incubator at $37^{\circ} \mathrm{C}$ and $5 \% \mathrm{CO}_{2}$. Medium was replaced every 2-3 days. After reaching more than $70 \%$ confluence, the cells were cultured for about 2-3 weeks in induction media for osteogenic differentiation, which was prepared with $\alpha$ MEM, $10 \mathrm{mM}$ L-ascorbic acids, 10\% FBS, antibiotics, $10 \mathrm{mM}$ $\beta$-glycerophosphate, and $100 \mathrm{nM}$ dexamethasone (Sigma, USA). Osteogenic medium was changed once every 2-3 days. Passage 3-5 cells were used for our studies.
2.2. LIPUS Treatment. hABMSCs were placed into $35 \mathrm{~mm}$ culture dishes at an initial density $1 \times 10^{4}$ cells/well. We carried out with three group conditions as follows: (1) control group (osteogenic differentiation media without LIPUS treatment), (2) osteogenic differentiation media with LIPUS treatment at a $20 \%$ duty cycle for 10 min once a day, and (3) osteogenic differentiation media with LIPUS treatment at a 50\% duty cycle for $10 \mathrm{~min}$ once a day (Figure 1). The hABMSCs were treated with pulsed ultrasound at $1 \mathrm{MHz}$ at duty cycles of $20 \%$ and $50 \%$ at low intensity of $50 \mathrm{~mW} / \mathrm{cm}^{2}$. The transducer was sterilized in $70 \%$ ethanol. A culture plate was placed above the transducer, and coupling gel (Choongwae Pharma Co., Korea) was covered on the transducer.

2.3. Cell Viability, DNA Proliferation, In Vitro Migration, and FE-SEM Morphological Analysis. The cell growth of hABMSCs was measured by WST-1 assay (EZ-Cytox Cell Viability Assay Kit, Daeillab Service Co., Ltd.) as manufacture's protocols. The formazan dye produced by viable cells was quantified by a multiwell spectrophotometer (Victor 3, Perkin Elmer, USA), measuring the absorbance of the dye solution at $460 \mathrm{~nm}$. DNA concentration was quantified by fluorometry using the CyQUANT Cell Proliferation Assay Kit (Invitrogen) and the $\lambda$ DNA standard (Invitrogen). The cell proliferation was measured using a Cytofluor II fluorescence multiwell plate reader with excitation of $485 \mathrm{~nm}$ and emission of $530 \mathrm{~nm}$ according to the instructions of the manufacturer. hABMSCs were cultured with or without LIPUS, and cell morphology was observed by phase contrast microscopy (Nikon TS100, Japan). In vitro cell migration was assessed by CytoSelect Wound Healing Assay as manufacture's protocols. Wound closure was measured by microscopy for up to $72 \mathrm{~h}$, and photographs were taken. hABMSCs were stimulated with exposure to LIPUS for $72 \mathrm{~h}$ except for the control (without stimulation group). Cell morphologies of hABMSCs were observed by a field-emission scanning electron microscope ((FESEM) JEOL, JSM-5410LV) at $2 \mathrm{kV}$ accelerating voltage.

2.4. Measurement of Mineralized Nodule Formation. Alkaline phosphatase (ALP) activity of the cell layer was quantified spectrophotometrically according to the instructions of the Sensolyte ALP Assay kit (AnaSpec, USA). After centrifugation at $2500 \times \mathrm{g}$ for $10 \mathrm{~min}$ at $4^{\circ} \mathrm{C}$, enzyme activity was calculated by measuring the yellow p-nitrophenol product formed at $405 \mathrm{~nm}$. The cells exposed at induction treatment were exposed to LIPUS for 2-3 weeks (10 min duration/day) except for control. Condition and nodule formation were checked routinely by phase contrast microscopy. Alizarin red is a common histochemical technique used to detect calcium deposits in mineralized tissues and cultures. Briefly, the ethanol-fixed cells and matrix were stained for $1 \mathrm{~h}$ with $40 \mathrm{mM}$ Alizarin red-S ( $\mathrm{pH} 4.2$ ) and extensively rinsed with water. After photography, the bound stain was eluted with $10 \%$ (wt/vol) cetylpyridinium chloride, and Alizarin red-S in samples was quantified by measuring absorbance at $544 \mathrm{~nm}$. Vitamin C, $\beta$-glycerophosphate, Alizarin red-S, and cetylpyridinium chloride were obtained from SigmaAldrich (St. Louis, MO, USA). hABMSCs were also cultured 


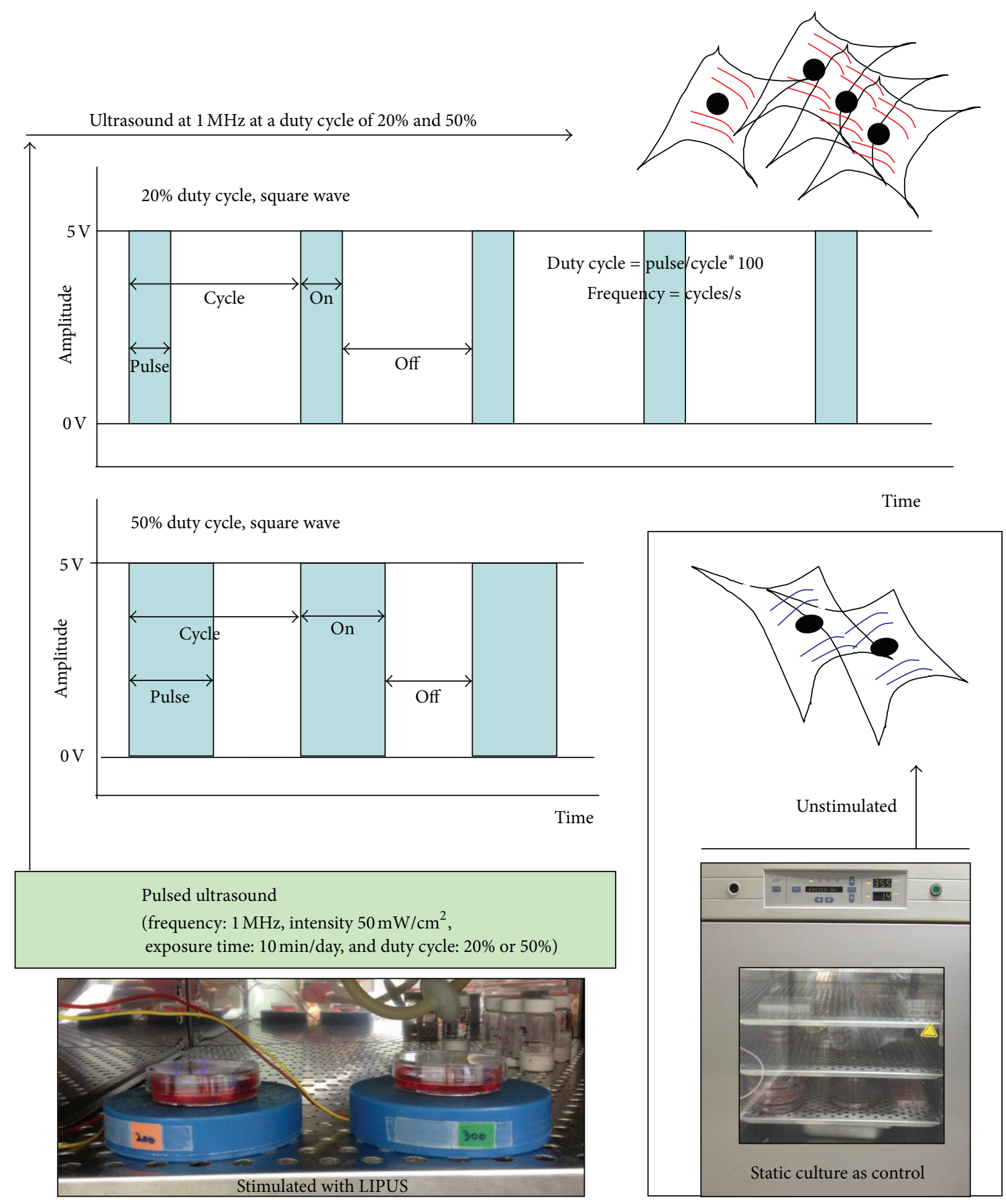

FIGURE 1: Schematic diagram of LIPUS treatment (frequency: $1 \mathrm{MHz}$, intensity: $50 \mathrm{~mW} / \mathrm{cm}^{2}$, exposure time: $10 \mathrm{~min} / \mathrm{day}$, and duty cycle: $20 \%$ or $50 \%$ ), as compared to static culture as control.

in osteogenic medium for 2-3 weeks in order to investigate assessment of mineralization using von Kossa staining, with and without LIPUS. Cells were fixed with 4\% (wt/vol) formaldehyde in PBS during $15 \mathrm{~min}$. And, the cells were incubated in 5\% (wt/vol) silver nitrate (Sigma-Aldrich, USA) for 1 hour on the UV light condition, followed by incubation in $5 \%$ (wt/vol) sodium thiosulfate (Sigma-Aldrich, USA) for

Time 

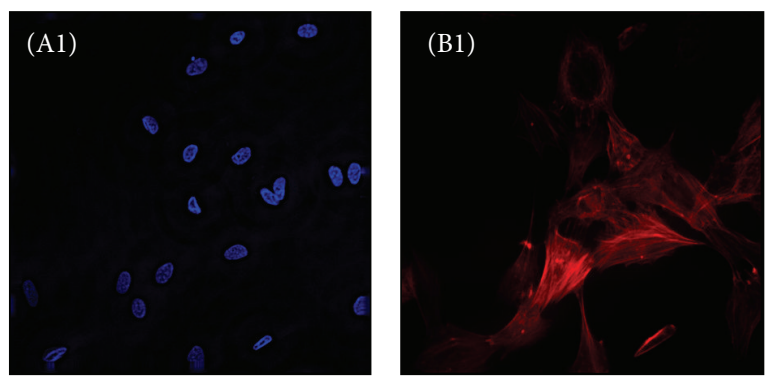

(a)
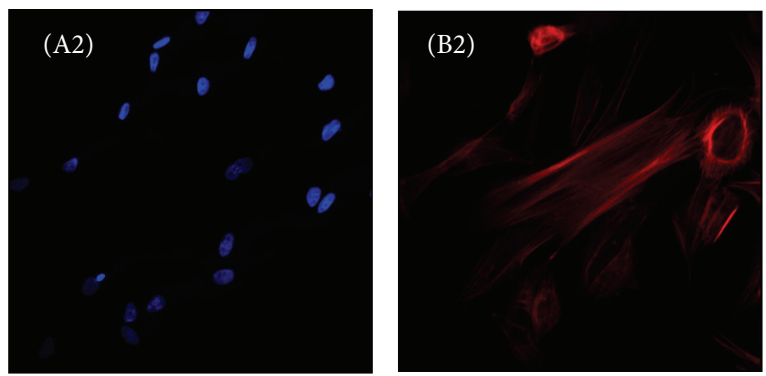
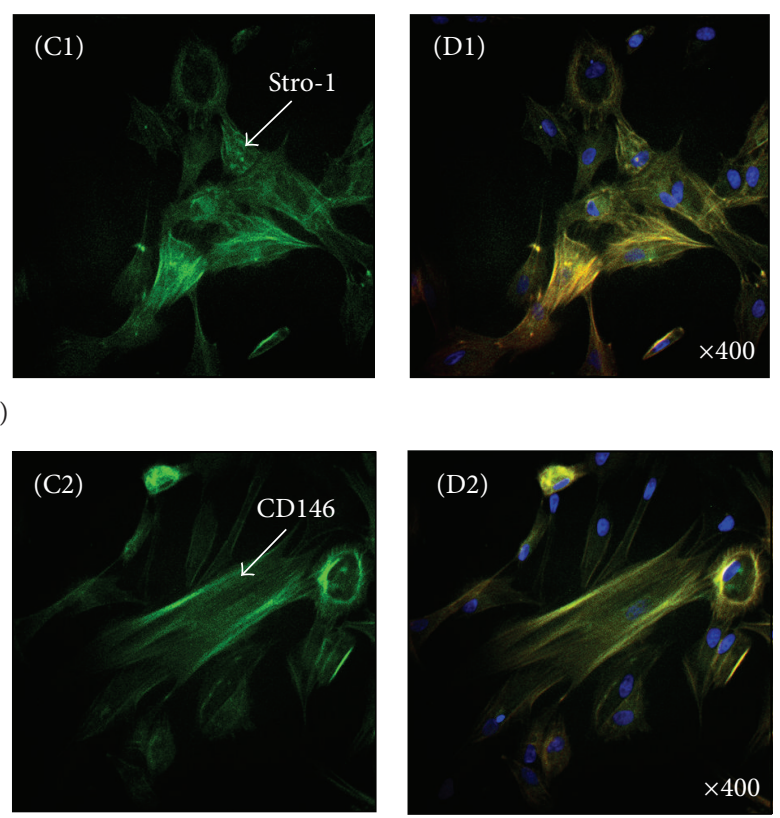

(b)

Figure 2: Representative immunocytochemistry images of hABMSCs. Fluorescence images of hABMSCs showed cell nuclei (A1), actin filaments (B1), Stro-1 (C1), and merged images (D1) of the fluorescence stains (a). Fluorescence images of hABMSCs showed cell nuclei (A2), actin filaments (B2), CD146 (C2), and merged images (D2) of the fluorescence stains (b) as MSC markers.

osteogenic factors. After 10 days in OSS culture, total RNA was isolated with TRIzol reagent (Invitrogen) and used to synthesize cDNA using a first-strand cDNA synthesis kit (Invitrogen) according to the instructions of the manufacturer. The human primers used in this study are listed in Table 1. RNA was extracted from the cell cultures at 14 days after the addition of differentiation media. These extracts were subjected to RT-PCR analysis with CD29, CD44, COL1, OCN, and GAPDH as the positive control. The products were separated by electrophoresis on a $1 \%$ agarose gel (SeaKem ME; FMC Bioproducts) and visualized by ultraviolet-induced fluorescence. Each band was normalized to a housekeeping gene expressed in the same amount in the different samples. Expression levels of gene areas were measured using ImageJ 1.45 s (National Institutes of Health).

2.6. Confocal Microscopy and Immunohistochemistry. The cells were washed in phosphate buffered saline ((PBS) SigmaAldrich, Milwaukee, WI, USA), fixed in a 4\% paraformaldehyde solution (Sigma-Aldrich, Milwaukee, WI, USA) for $20 \mathrm{~min}$, and permeabilized with $0.2 \%$ Triton X-100 (SigmaAldrich, Milwaukee, WI, USA) for $15 \mathrm{~min}$. Cells were incubated with TRITC conjugated phalloidin, antiosteocalcin, its secondary antibody (Cat. no. AB10911, Millipore), and DAPI (Millipore, Billerica, MA, USA) according to the manufacture's protocol. Cytoskeleton organization was visualized using an actin cytoskeleton and focal adhesion staining kit (FAK100; Millipore, Billerica, MA) according to the manufacturer's instruction. In addition, stem cell surface markers of mesenchymal stem cells were captured using Stro1 (Santa Cruz Biotechnology, USA) and CD146 (BD Bioscience, USA) according to the manufacturer's instruction. Cells were mounted in glycerol/buffer on a glass slide after extensive washing with PBS. Images of labeled cells were obtained by a Confocal Laser Scanning Microscope (Carl Zeiss, LSM710) and histogram was extracted using MATLAB (R2013a, Mathworks, USA) to investigate the diverse cellular dynamics labeled with fluorescent indicators.

2.7. Statistical Analysis. Statistical analysis was carried out using the SAS Statistical Analysis System for Windows v8.2 (SAS Institute, Inc., Cary, NC, USA). Statistical significance between control and treatment groups was compared with two-way ANOVA and Duncan's multiple range tests at ${ }^{*} P<$ 0.05 . The data were reported as the mean \pm standard deviation.

\section{Results}

3.1. Immunocytochemistry Analysis of hABMSCs for Stem Cell Markers. For investigating stem cell characteristics, we measured the cell morphologies of hABMSCs via immunocytochemistry and analyzed positive markers. Representative immunocytochemistry images of hABMSCs are shown in Figure 2(a). Fluorescence images of hABMSCs show cell nuclei (A1), actin filaments (B1), Stro-1 (C1), and merged images (D1) of the fluorescence stains (Figure 2(b)). Fluorescence images of hABMSCs showed cell nuclei (A2), 

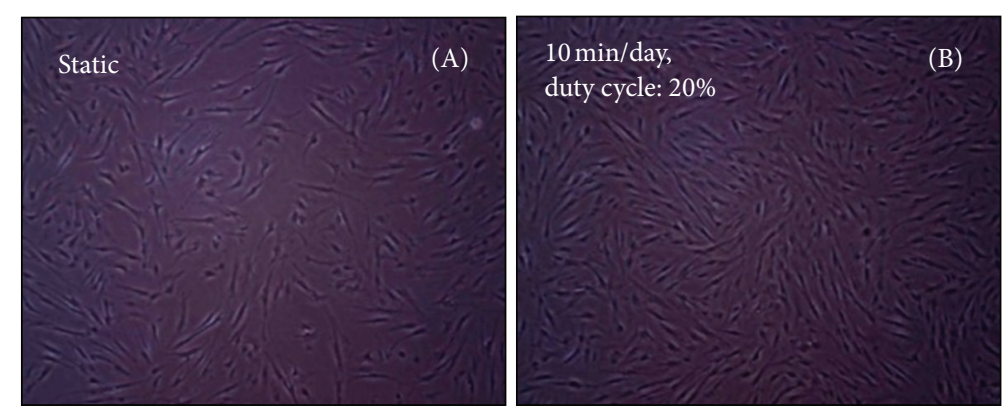

(a)
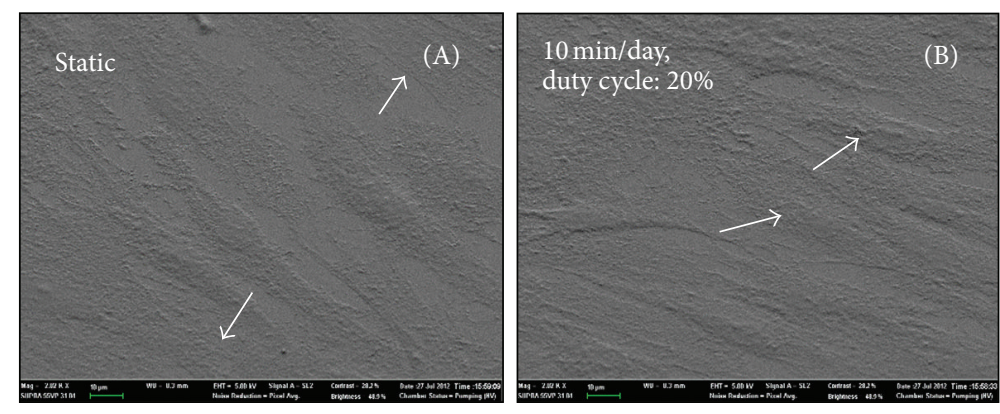

(b)

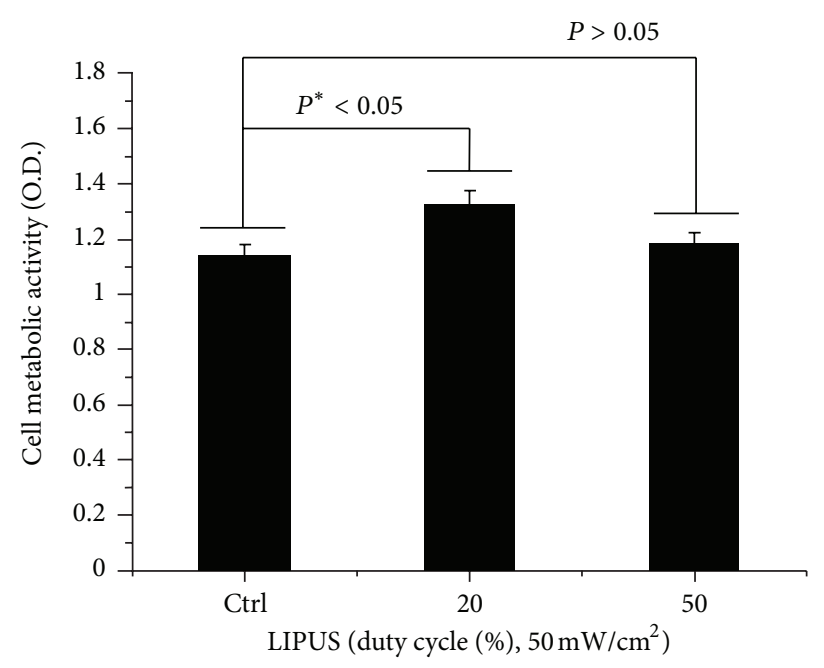

(c)
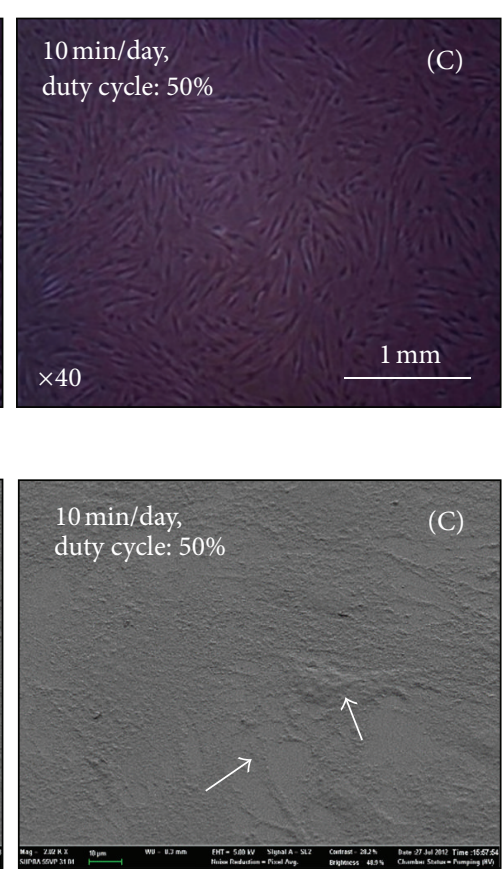

(C) 
TABLE 1: Primers used for RT-PCR.

\begin{tabular}{|c|c|c|c|}
\hline Gene & Accession number & Primer sequence & Predicted size (bp) \\
\hline CD29 & NM_002211 & $\begin{array}{l}5^{\prime} \text {-AATGAAGGGCGTGTTGGTAG-3' } \\
5^{\prime} \text {-CGTTGCTGGCTTCACAAGTA-3' }\end{array}$ & 337 \\
\hline CD44 & X55938 & $\begin{array}{c}5^{\prime} \text {-ACCGACCTTCCCACTTCACAG-3' } \\
5^{\prime} \text {-GCACTACACCCCAATCTTCAT-3' }\end{array}$ & $168-200$ \\
\hline Col-I & NM_000088 & $\begin{array}{l}5^{\prime} \text {-CTGGCAAAGAAGGCGGCAAA-3' } \\
5^{\prime} \text {-CTCACCACGATCACCCACTCT-3' }\end{array}$ & 503 \\
\hline OCN & X53698.1 & $\begin{array}{l}5^{\prime} \text {-CATGAGAGCCCTCACACTC-3' } \\
5^{\prime} \text {-AGAGCGACACCCTAGACCG-3' }\end{array}$ & 315 \\
\hline GAPDH & AF017079 & $\begin{array}{l}5^{\prime} \text {-GGGCATGAACCATGAGAAGT-3' } \\
5^{\prime} \text {-CCCCAGCATCAAAGGTAGAA-3' }\end{array}$ & 497 \\
\hline
\end{tabular}

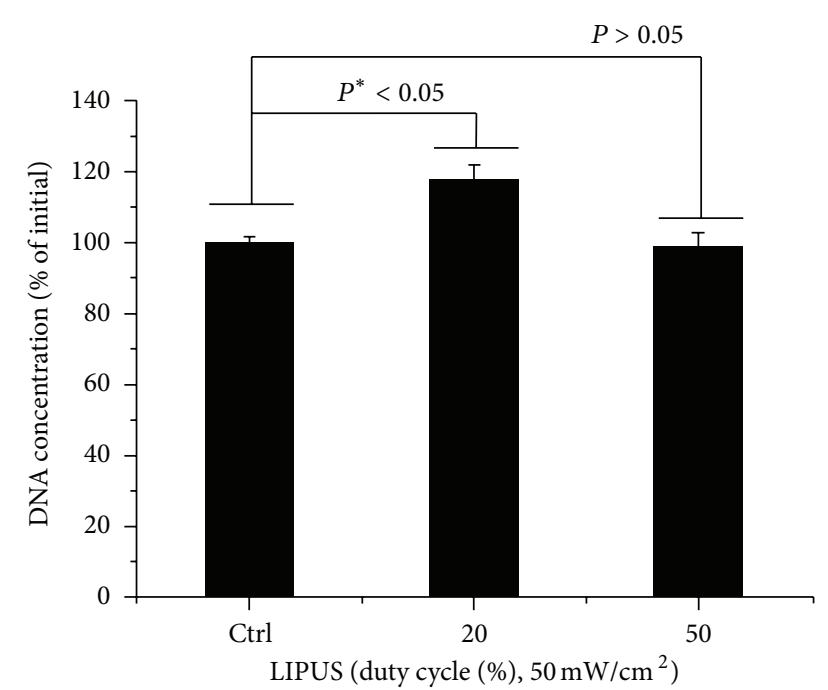

FIGURE 4: DNA concentration as percent of initial of hABMSCs measured using CyQUANT Cell Proliferation Assay Kit (D) $(n=3)$.

on effects of LIPUS (Figure S1; see Supplementary Material available online at http://dx.doi.org/10.1155/2013/269724). Figure S1 shows representative optical microscopic images of hABMSCs stimulated for 4 days as follows: Figure S1(A) is FBS $(+)$ proliferation media with cells in static condition (a), at 20\% duty cycle under LIPUS (b), and at 50\% duty cycle under LIPUS (c). Figure S1(B) is FBS (-) media with cells in static condition (a), at $20 \%$ duty cycle under LIPUS (b), and at 50\% duty cycle under LIPUS (c). Cell metabolic viability as optical density of hABMSCs between FBS (+) and FBS (-) groups was measured using WST-1 (Figure S1(C)). This showed that LIPUS treatment of ABMSCs has a limit to cell growth, migration, and differentiation under the FBS (-) condition. Our initial expectation was that the cells would be grown and confluent in culture dishes receiving the LIPUS treatment without the addition of FBS (-). Based on these results, we can conclude that the LIPUS treatment supports cell growth or at least give synergic effects to cells.

3.3. Cell Proliferation and In Vitro Migration. The proliferation of cells stimulated at $20 \%$ duty cycle LIPUS increased by $10 \%$ compared to the control $\left({ }^{*} P<0.05\right)$. As a consequence, both cell viability and cell proliferation were significant at duty cycle of $20 \%$ during $10 \mathrm{~min} /$ day LIPUS. Results of an in vitro migration assay of hABMSCs are shown in Figure 4. In vitro cell migration, shown as representative optical microscopic images of the LIPUS group compared to the static culture, shows the stimulation group exposed at $20 \%$ duty cycle LIPUS for $10 \mathrm{~min} /$ day as significantly different $\left({ }^{*} P<0.05\right)$ among groups (Figure 5). Exposing hABMSCs to LIPUS forces reveals signs of increased metabolic activity such as ion transportation, fibroblast migration, protein synthesis, and others. One interesting result from our study is that the cells in the lower duty cycle group were more proliferated and differentiated than those in the other groups. Figure S2(A) shows in vitro cell migration as representative optical microscopic images with FBS (+) group under LIPUS treatment compared to the static culture. This showed that the cell migration of LIPUS group exposed at $20 \%$ duty cycle was faster than $50 \%$ duty cycle group (B). Figure S2(B) indicated in vitro cell migration as representative optical microscopic images with FBS (-) group under LIPUS treatment compared to static culture. LIPUS treatment with absence (-) of FBS in osteogenic media was ineffective on cell growth and migration. Based on the result, we could ascertain that LIPUS treatment had a synergy effect on cell proliferation and migration when exposing presence of FBS in culture media.

\subsection{Gene Expression of Osteoblastic Differentiation Markers.} The expression of genes associated with osteoblastic differentiation was examined using RT-PCR to investigate the effect of LIPUS on gene expression. Figure 6(a) shows RTPCR analysis of the static and stimulated cell cultures after a 2-week period. Expression levels (Figure 6(b)) of CD29 (A), CD44 (B), COL1 (C), and OCN (D) at 2 weeks were significantly higher in LIPUS treatment. Stimulation groups exposed during $10 \mathrm{~min} /$ day at $20 \%$ duty cycle (for CD 44 ) or $50 \%$ duty cycle (for OCN) were significantly different $\left({ }^{*} \mathrm{P}<\right.$ 0.05 ) between the groups. Expression levels were measured using Image $1.45 \mathrm{~s}$. As a result of these increases in expression, we can say that LIPUS is affiliated with mechanotransduction.

3.5. Enhanced Osteogenic Differentiation of hABMSCs via LIPUS. We investigated the ALP activity of hABMSCs stimulated with LIPUS for 7 days. LIPUS groups exposed during $10 \mathrm{~min} /$ day at $20 \%$ or $50 \%$ duty cycle showed significant 

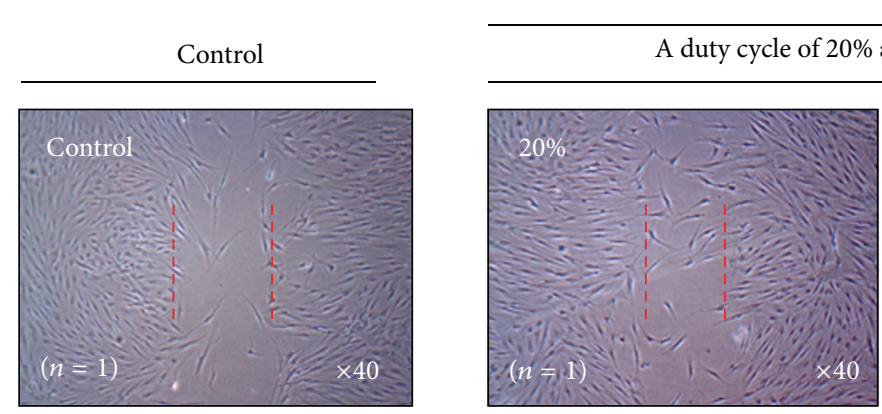

After $24 \mathrm{~h}$
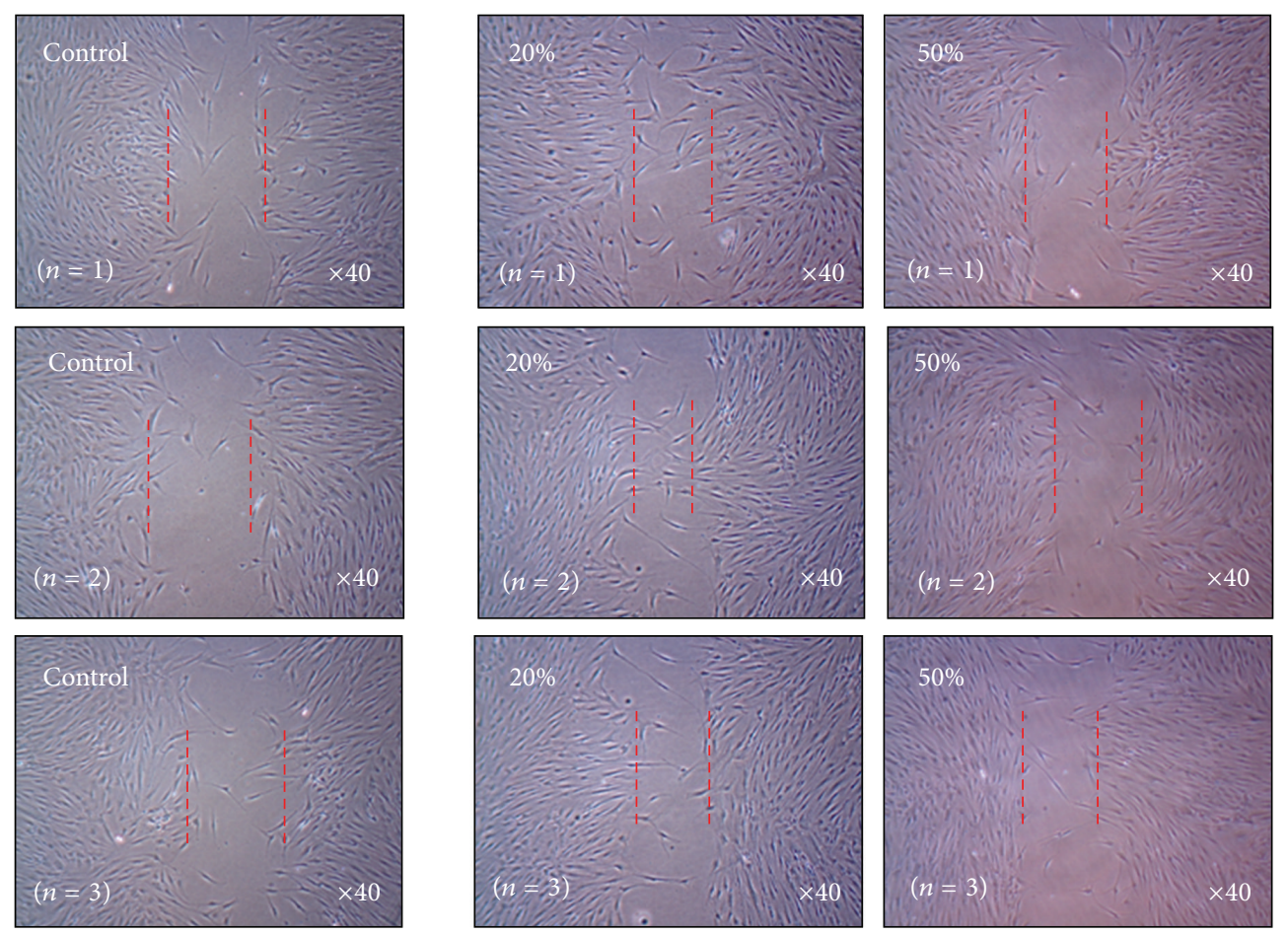

(a)

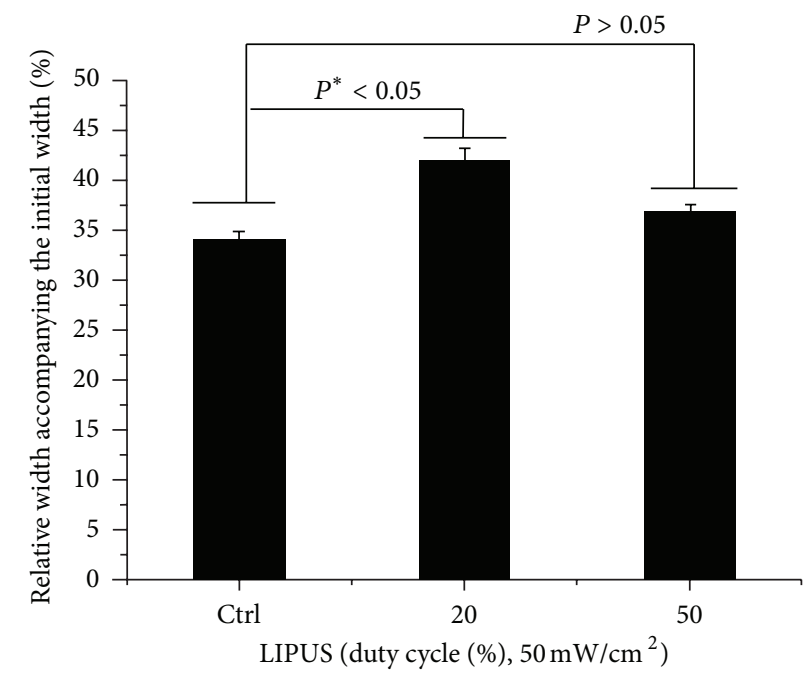

(b)

FIGURE 5: In vitro cell migration as representative optical microscopic images of LIPUS group compared to the static culture (a), indicating that the stimulation group exposed at $20 \%$ duty cycle LIPUS for $10 \mathrm{~min} /$ day was significantly different $\left({ }^{*} P<0.05\right)$ among groups $(\mathrm{b})(n=3)$.

differences between groups (Figure 7). An early osteoblastic marker has relevance to the gene expression of other osteoblastic differentiation markers. Figures $8(\mathrm{a})-8(\mathrm{c})$ show representative images of hABMSCs after Alizarin red and von Kossa staining treatment in static condition (a), at $20 \%$ duty cycle under LIPUS (b), and at 50\% duty cycle under LIPUS (c) at 2-3 weeks after the addition of differentiation media. Staining in the LIPUS group with $20 \%$ duty cycle was much more intense compared to the control, while the $50 \%$ duty cycle group was a bit generated. Figure 8(d) shows representative optical microscopic images of hABMSCs after Alizarin red staining of cells in static condition (a) at $20 \%$ duty cycle under LIPUS (b) and at 50\% duty cycle under LIPUS (c) at 2-3 weeks. Staining in the LIPUS group at 


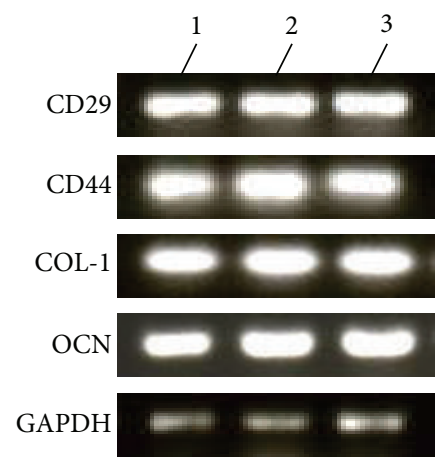

(1) Control

(2) $20 \%$ duty cycle, $50 \mathrm{~mW} / \mathrm{cm}^{2}$

(3) $50 \%$ duty cycle, $50 \mathrm{~mW} / \mathrm{cm}^{2}$

(a)

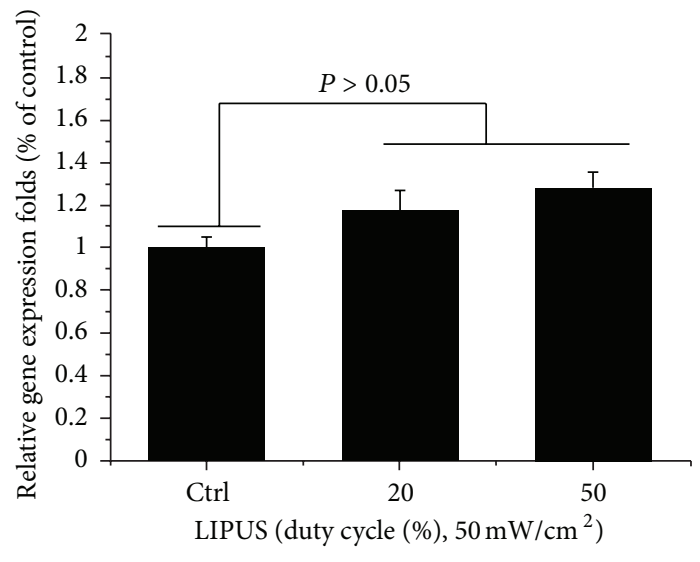

(A) $\mathrm{CD} 29$

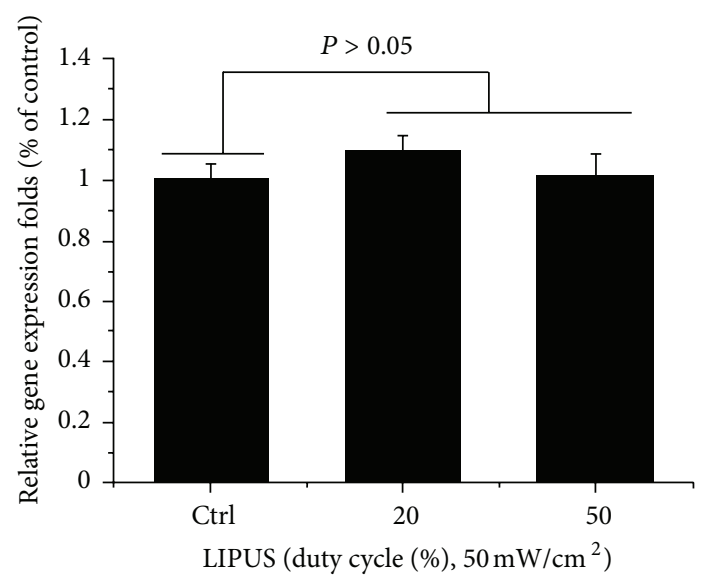

(C) COL-1

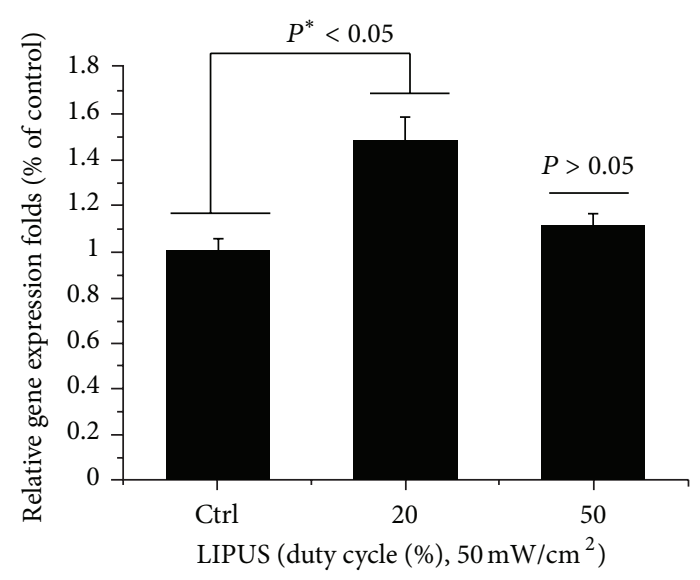

(B) $\mathrm{CD} 44$

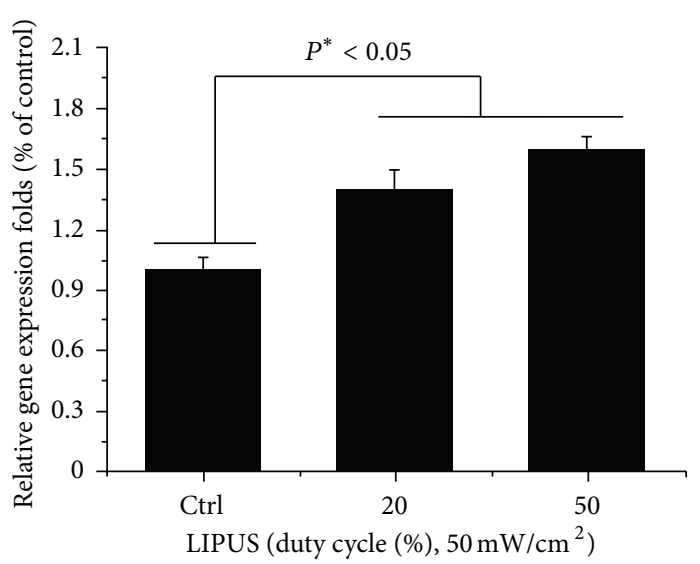

(D) $\mathrm{OCN}$

(b)

FIGURE 6: RT-PCR analysis of cell cultures between LIPUS treatment and static culture for 2 weeks. Expression of genes associated with the osteoblastic differentiation was examined using real time PCR to investigate the effect of LIPUS treatment on gene expression (a). Expression levels (b) of CD29 (A), CD44 (B), COL1 (C), and OCN (D) at 2 weeks were significantly higher in LIPUS treatment. Stimulation groups exposed during $10 \mathrm{~min} /$ day at $20 \%$ duty cycle (in CD44) or $50 \%$ duty cycle (in OCN) were significantly different $\left({ }^{*} P<0.05\right)$ among groups. 


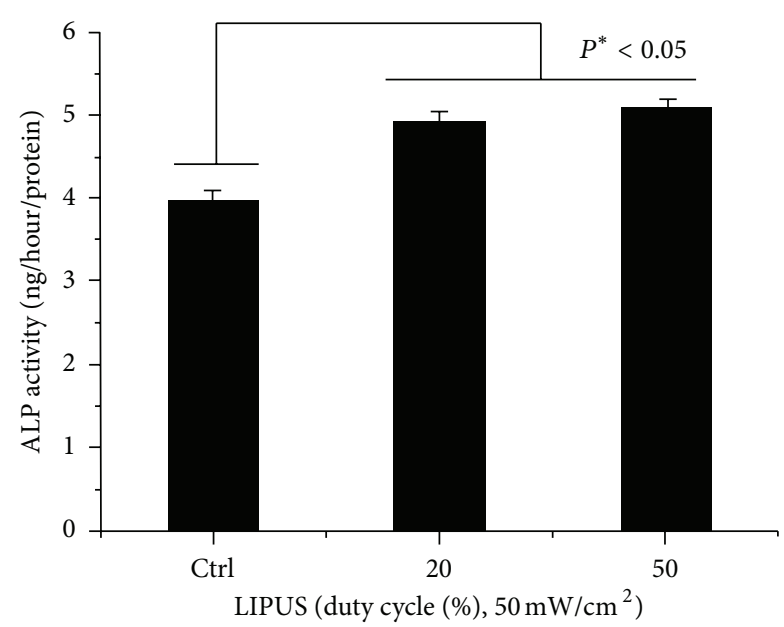

FIgURE 7: ALP activity cultured in different types of hABMSCs stimulated with LIPUS for 1 week. LIPUS groups exposed during $10 \mathrm{~min} /$ day at $20 \%$ or $50 \%$ duty cycle were significantly different $\left({ }^{*} P<0.05\right)$ among groups $(n=3)$.

$20 \%$ duty cycle was more intense than the static group. hABMSCs cultured with LIPUS under conditioned media showed increased calcium contents. Mineralization of von Kossa staining is shown in Figure 8(e). The short-pulsed duty cycle group was interestingly increased compared to the longer duty cycle group. Representative images ware shown in Figures $8(\mathrm{~d})$ and $8(\mathrm{e})$. The LIPUS group exposed at $20 \%$ duty cycle was significantly different $\left({ }^{*} P<0.05\right)$ than either of the other groups. This result shows that optimal LIPUS with the proper intensity, duty cycle, and time could enhance the in vitro growth and osteogenic differentiation of hABMSCs.

3.6. Fluorescence Microscopy Analysis. Representative optical fluorescence microscopy images (Figure 9(a)) of hABMSCs cultured for 7 days in static conditions (A) or LIPUS induction at $20 \%$ duty cycle (B) or $50 \%$ duty cycle (C) after the addition of differentiation media: cell nuclei, actin filaments, osteocalcin and merged images of the fluorescence stains. Fluorescence images showed more lining-up observation at stimulation groups compared to control group (arrows: cell motion). Actin and vinculin were imaged to investigate possible rearrangements, reorientations, or both of cytoskeleton elements in hABMSCs exposed to LIPUS. Overall, actin microfilaments and vinculin intermediate filament structures were somewhat changed under LIPUS treatment. Figure 9(b) shows representative confocal laser microscopy images of hABMSCs cultured for 7 days in static conditions (A) or LIPUS induction at $20 \%$ duty cycle (B) or $50 \%$ duty cycle (C) after the addition of differentiation media: cell nuclei, actin filaments, osteocalcin, and merged images of the fluorescence stains. Confocal laser microscopy images showed more intense observations in the LIPUS induction groups compared to the control group. Signal transduction via LIPUS ultimately could enhance adhesion molecules and then finally enhance osteogenesis. The results suggest that the LIPUS enhances the osteogenic differentiation and maturation of hABMSCs. Figure 9(c) indicates relationship histogram of brightness level in florescence cell image treated by LIPUS induction. According to histogram of brightness, we could ascertain that LIPUS treatment had more intense rather than that of control.

\section{Discussion}

In this study, we investigated in vitro effects of LIPUS on the growth and osteogenic differentiation of hABMSCs for tooth tissue engineering. In particular, we found out effects of duty cycle of ultrasound, which could be delivered to tissues. Therefore, LIPUS which was $20 \%$ and $50 \%$ duty cycles during 10 min per day was induced.

LIPUS is a form of physical energy that can be delivered into living tissue as acoustic intensity waves. Radical changes in density inherent in a healing tissue may well establish the gradients of physical strain [14]. Further, absorption of the ultrasound signal also results in energy conversion to heat $[15,16]$. Though this thermal effect is extremely small for low frequency ultrasonic waves, well below $1^{\circ} \mathrm{C}$, some enzymes, such as matrix metalloproteinase-1 or collagenase, are exquisitely sensitive to small variations of temperature [15-17]. Therefore, ultrasound may serve to e-establish or normalize effective metabolic temperatures in tissue-healing regions $[15,18]$. Furthermore, incident radiation energy will be reflected at interfaces of distinct densities, resulting in complex gradients of acoustic pressure through the tissue [19]. The physical force produced by these intensity waves in living tissue can result in chemical events at the cellular level [20-22]. This may be generated through several possible mechanisms. The compression of microbubbles and acoustic streaming could have a direct effect on cell membrane permeability $[23,24]$. Moreover, physical pressure exposed to LIPUS at the cell surface affected activation of cation channels [25]. The LIPUS also may influence the attachment of the cytoskeleton to the extracellular matrix [26]. In our study, actin and vinculin were captured to find out possible rearrangements, reorientations, or both of cytoskeleton elements in hABMSCs exposed to LIPUS. Namely, Actin microfilaments and vinculin intermediate filament structures were rearranged under LIPUS treatment.

In this report, we evaluated whether LIPUS exposure with various duty cycles initiates osteogenic differentiation in hABMSCs. Physical force serves as an extracellular signal to a variety of cells, including bone cells. Several researchers have found an increase in cellular proliferation [27-30], and the production of prostaglandin E2 [31, 32] after invocations of various types of biophysical stimulation of bone cells. Several studies have showed that ultrasound stimulation leads to enhancement in protein synthesis $[33,34]$ and collagen synthesis [35]. In vitro studies have demonstrated increased chondrogenesis by increased aggrecan expression [36] after treatment with LIPUS. Wang et al. [37] showed that ultrasound stimulation led to increased vascular endothelial growth factor mRNA and protein levels in human osteoblast cells. Our result indicated that LIPUS increased osteogenic differentiation as well as proliferation and migration of 


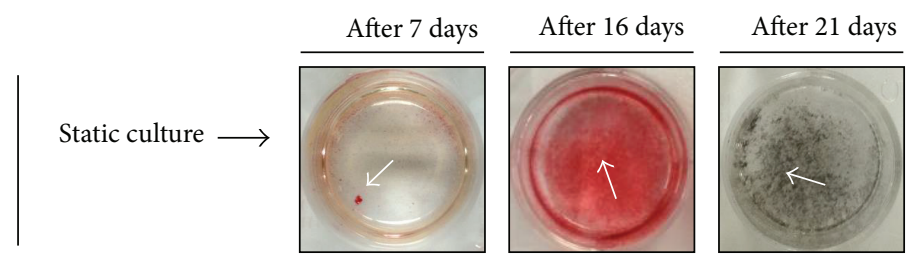

(a)
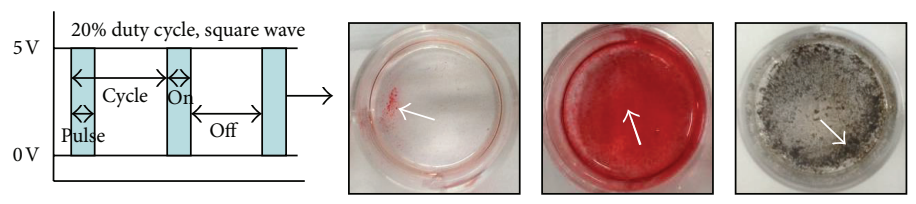

(b)
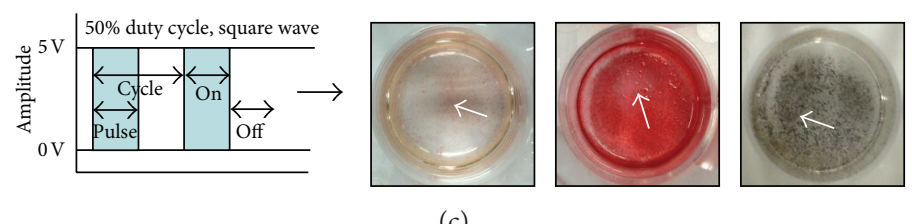

(c)
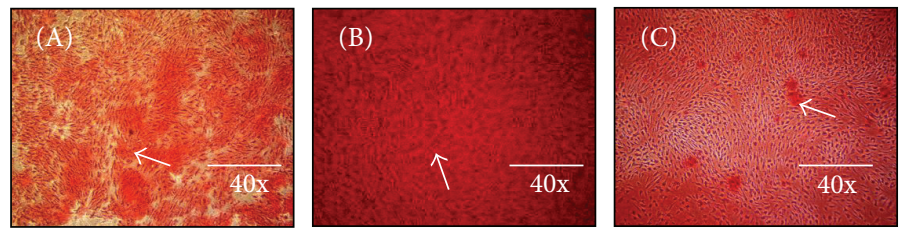

(d)
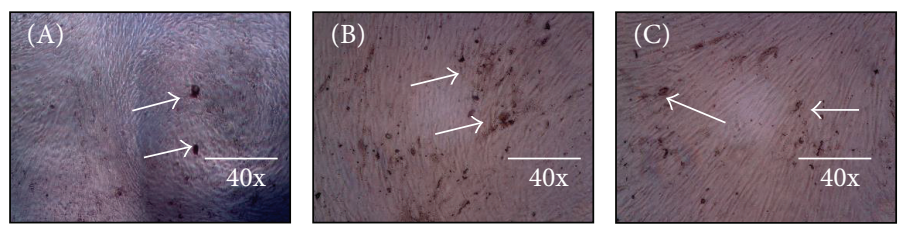

(e)

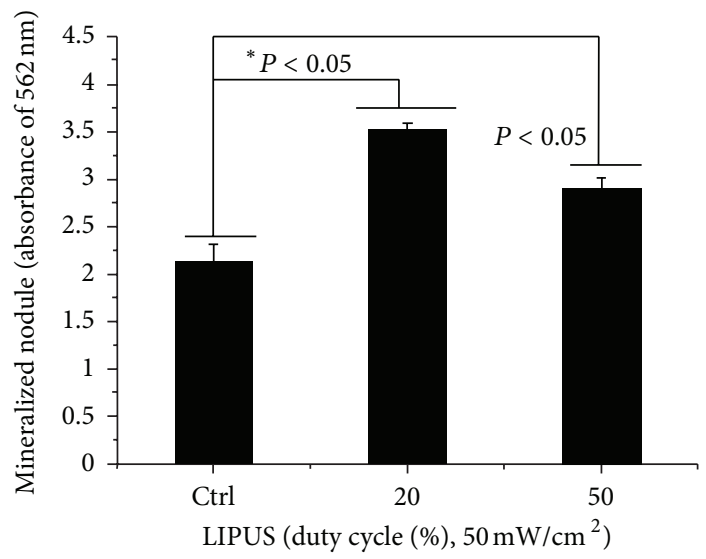

(f)

Figure 8: Representative images of hABMSCs after Alizarin red and von Kossa staining treatment in static condition (a), at $20 \%$ duty cycle (b), and at 50\% duty cycle under LIPUS treatment (c) at 2-3 weeks after the addition of osteogenic differentiation media. Representative optical microscopic images of hABMSCs after Alizarin red staining treatment in static condition (A), at 20\% duty cycle under LIPUS (B), and at $50 \%$ duty cycle under LIPUS (C) at 2-3 weeks were indicated (d). Mineralization images of von Kossa staining are shown in Figure 8(e). The short-pulsed duty cycle group was interestingly increased compared to the longer duty cycle group. Representative images were shown in Figures $8(\mathrm{~d})$ and $8(\mathrm{e})$. Figure $8(\mathrm{f})$ shows the optical density value of a mineralized nodule (absorbance of $562 \mathrm{~nm}$ ) measured after destaining treatment. 
(A) Control
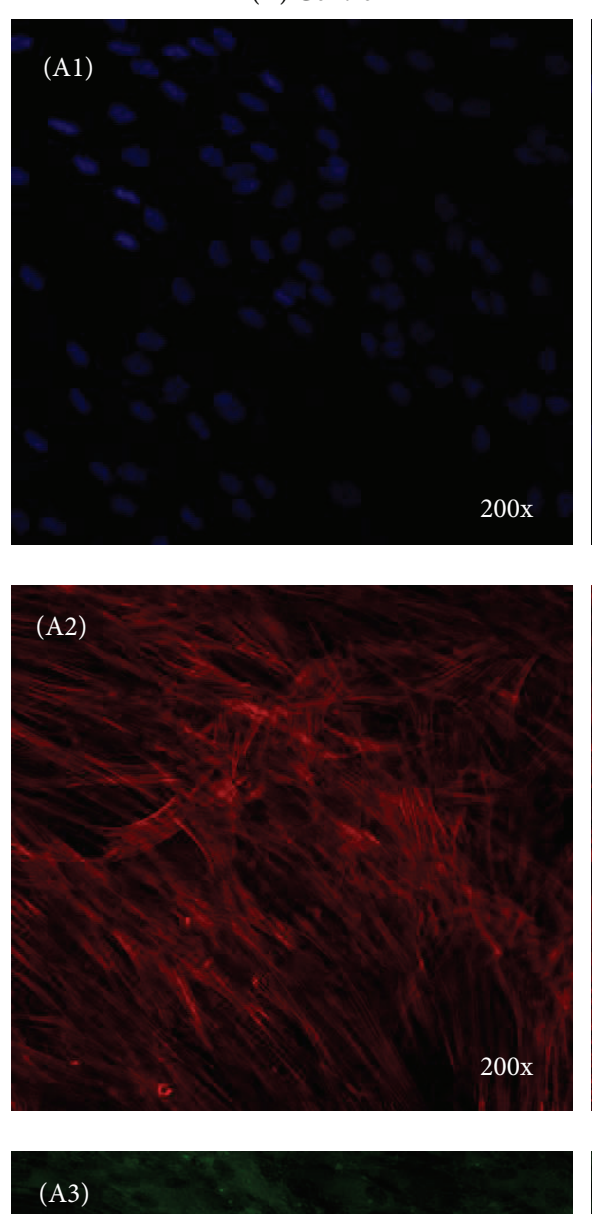

200x

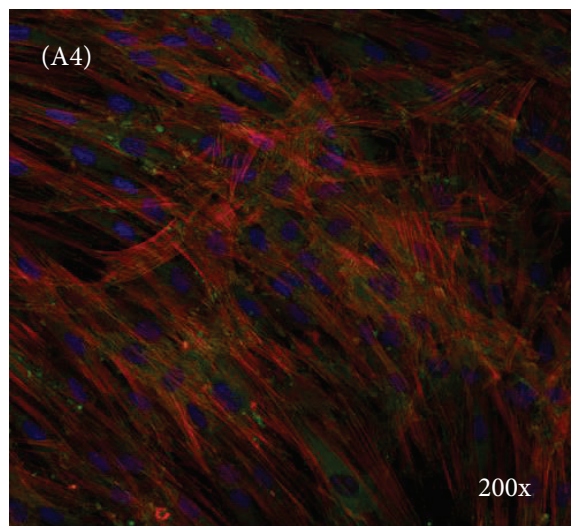

(B) LIPUS, duty cycle $20 \%$
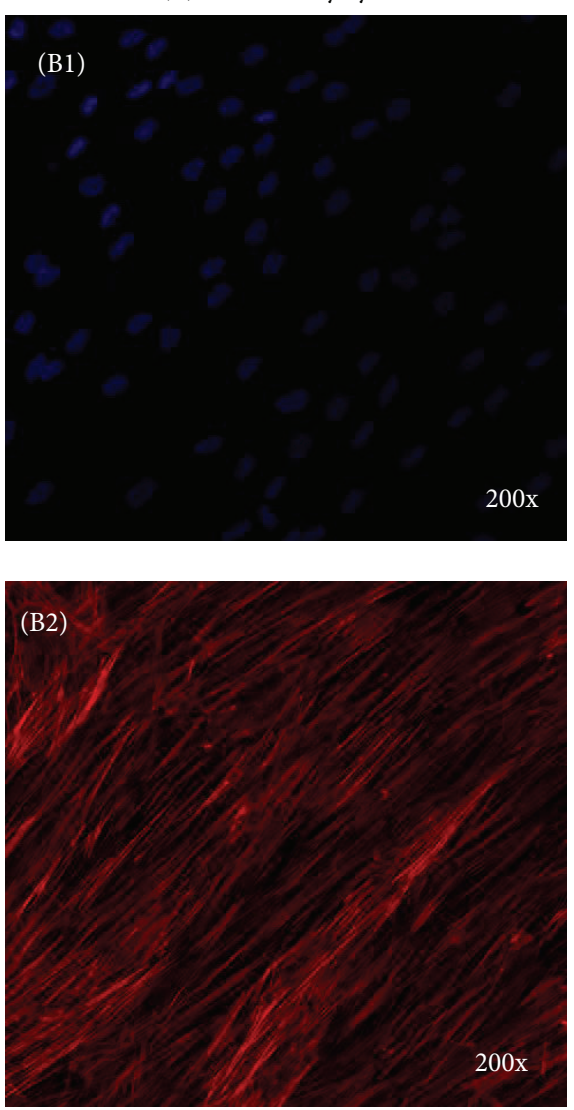

(C2)

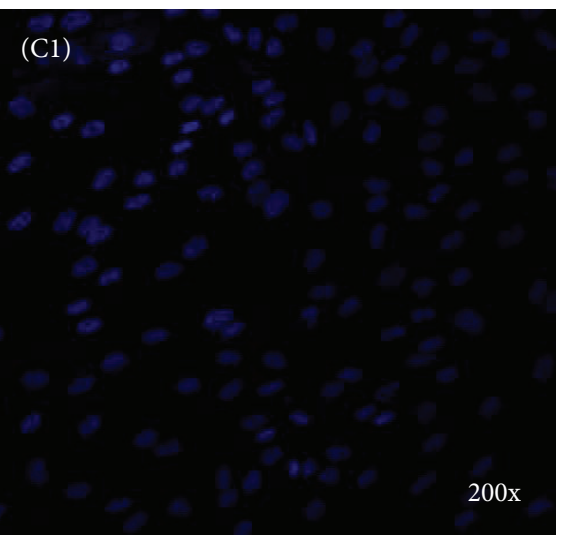

$200 x$

(C3)

$200 x$

$200 x$

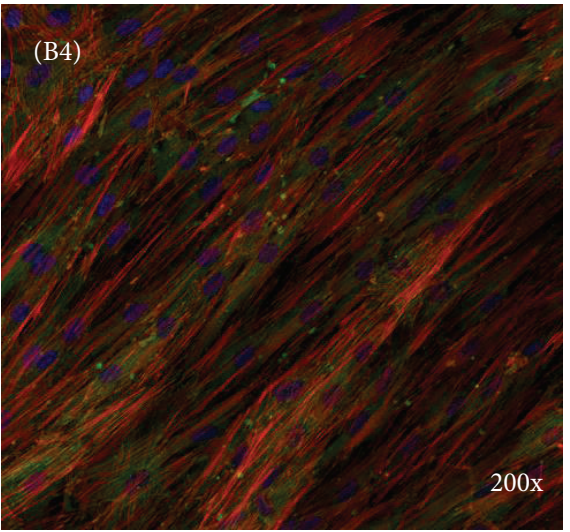

(a)

Figure 9: Continued. 
(A) Control
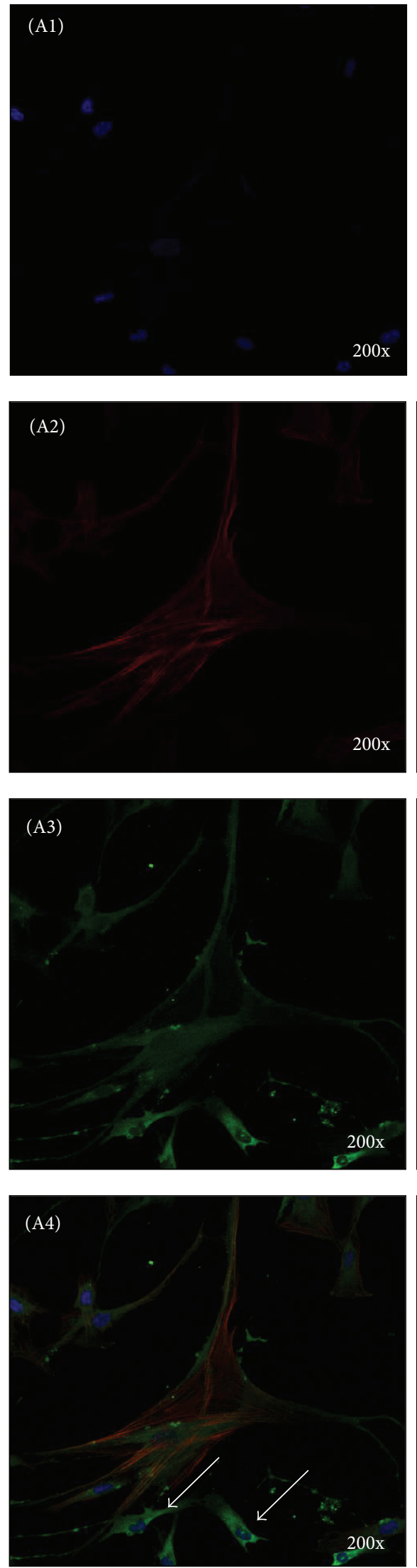

(C) LIPUS, duty cycle 50\%
(B) LIPUS, duty cycle $20 \%$

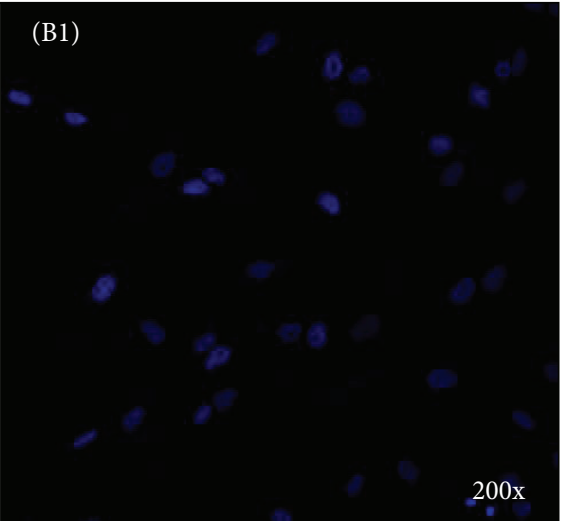

(B2)

$200 x$
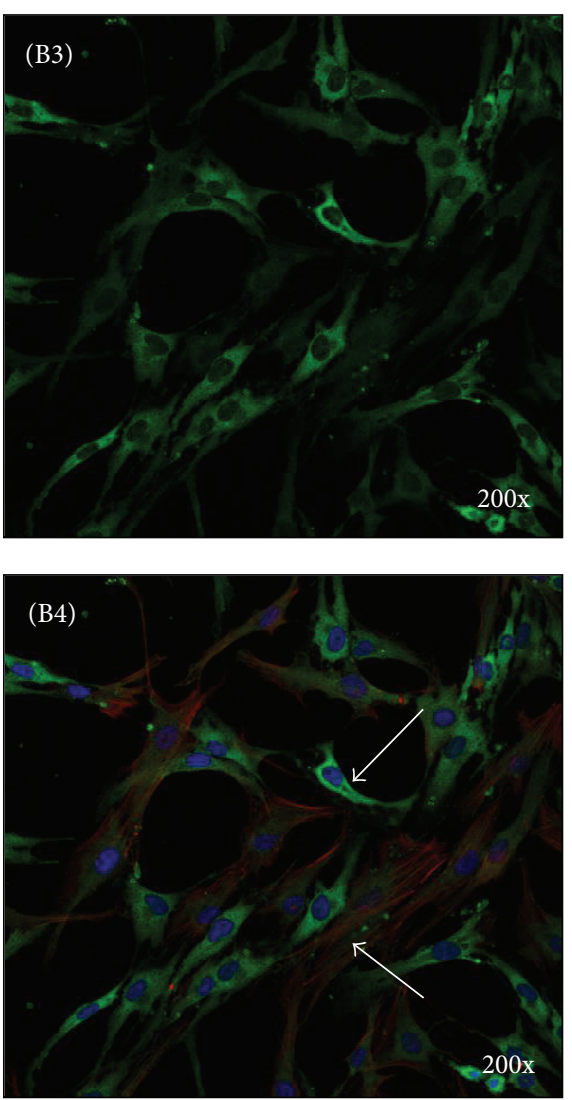

(b)

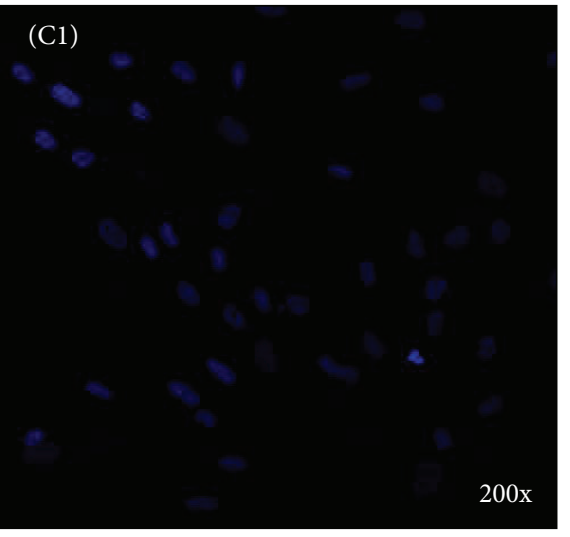

(C2)

$200 x$
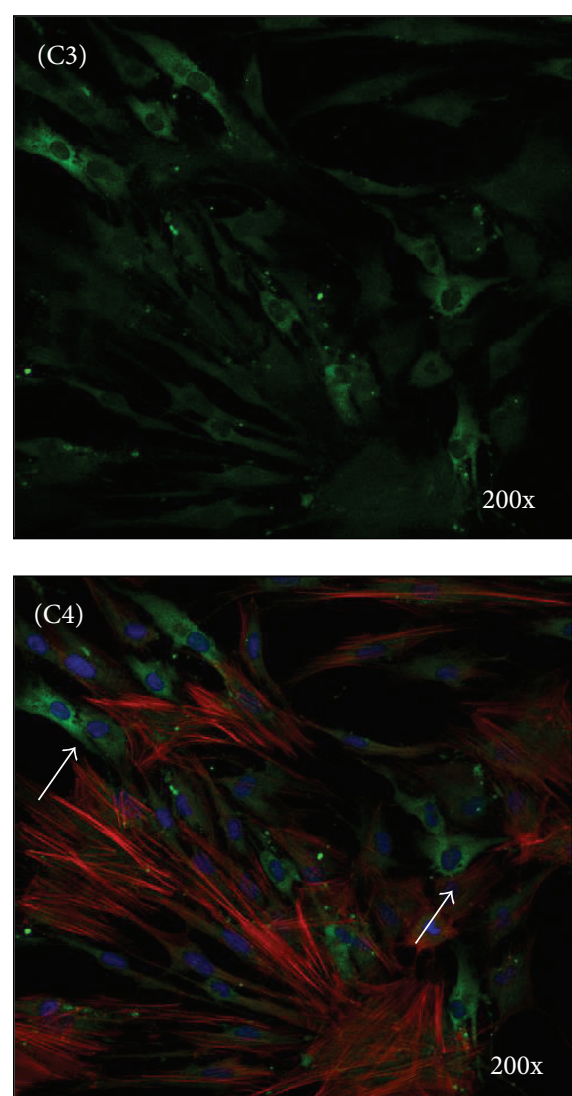

$200 x$

FIGURE 9: Continued. 


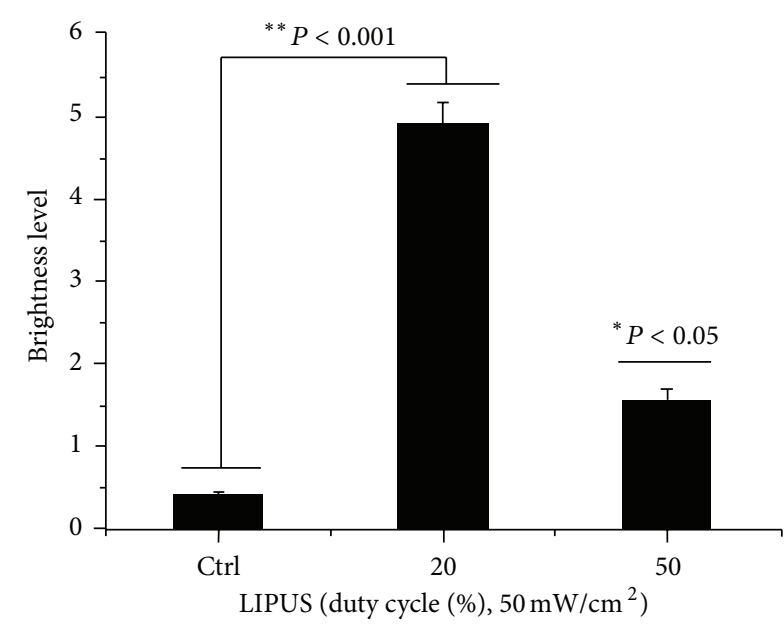

(A)

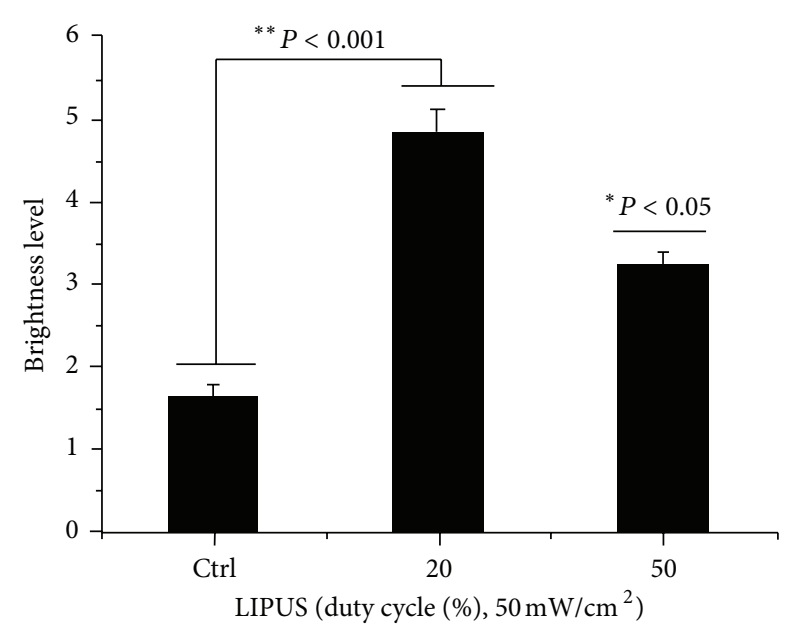

(B)

(c)

FIGURE 9: (a) Representative confocal laser microscopy images of hABMSCs cultured for 7 days in static conditions (A) or LIPUS induction at $20 \%$ duty cycle (B) or $50 \%$ duty cycle (C) after the addition of differentiation media: cell nuclei (blue), actin filaments (red), vinculin (green), and merged images of the fluorescence stains. Confocal laser microscopy images showed more intense observation in the LIPUS group compared to the control group. (b) Representative confocal laser microscopy images of hABMSCs cultured for 7 days in static conditions (A) or LIPUS induction at $20 \%$ duty cycle (B), or $50 \%$ duty cycle (C) after the addition of differentiation media: cell nuclei (blue), actin filaments (red), osteocalcin (green), and merged images of the fluorescence stains. Confocal laser microscopy images showed more intense observation in the LIPUS group compared to the control group. (c) Brightness level of vinculin (A) and osteocalcin (B) in florescence cell image treated by LIPUS induction.

hABMSCs, which is consistent with previous studies. Interestingly, migration and osteogenic differentiation were influenced by change of LIPUS duty cycle. The finding that duty cycle can influence proliferation and differentiation was not reported yet. Hence, as a future work, combining a variety of duty cycle and duration can be meaningful.

Dental implants are extremely useful for the restoration of oral function, including mastication, as well as for the aesthetic improvement in patients with tooth loss [38]. However, the success rate of implant is relatively low for the patients with poor quantity and quality of alveolar bone and with some diseases like osteoporosis. In the meantime, there is also an increasing need for shorter rehabilitation time in order to alleviate the inconvenience for patients [39]. Therefore, seeking an easy and effective method to improve and enhance the osseointegration of dental implants is necessary for dental clinicians and researchers. Some researchers have demonstrated that ultrasound stimulation increased surface expression of integrins in osteoblasts and that long-term stimulation also enhanced osteoblastic differentiation and inhibited osteoclastogenesis [40]. One study indicates that the cell population was increased significantly when osteoblasts were treated with ultrasound [41]. In the same manner, our study showed that ultrasound stimulation can enhance proliferation, migration, and differentiation of hABMSCs. In our previous study, proper ultrasound stimulation enhanced the proliferation of hABMSCs [13]. Yet, the study did not show how ultrasound stimulation affected on the migration and differentiation of hABMSCs. Hence, this study can be beneficial to dental regeneration.
The underlying mechanism of the mechanotransduction pathway involved in cellular responses to LIPUS is largely unknown. It has been demonstrated that LIPUS exposure increased cyclooxygenase- 2 mRNA expression which leads to an increase in PGE2 (prostaglandin E2) and plays an essential role in the osseointegration of dental implants [4244]. Another research showed that extremely low frequency pulsed electromagnetic fields (ELF-PEMFs) could enhance early cell proliferation in hABMSCs-mediated osteogenesis and accelerate the osteogenesis [45]. VEGF is a key regulator for angiogenesis which is essential to fracture healing [46]. Even though its concrete signals pathway is complicated and remains to be thoroughly understood, the present studies indicate that LIPUS has a favorable influence on osteoblasts.

It is foreseeable that miniaturized ultrasonic transducers may have the potential to improve patients' therapeutic experience. By using the treatment of LIPUS, the rehabilitation time may be shortened due to the acceleration of bone tissue regeneration. At the same time, the osseointegration can be strengthened, and a higher survival rate of the implants will ensue [47]. This indicated that optimal LIPUS device or stimulator with the proper intensity, duty cycle, and time could enhance the in vitro growth and osteogenic differentiation of dental stem cells for tooth tissue engineering.

\section{Conclusions}

The objective of this study was to find out the effects of LIPUS on proliferation and osteogenic differentiation of hABMSCs, 
which were treated with an intensity of $50 \mathrm{~mW} / \mathrm{cm}^{2}$ and exposure time of $10 \mathrm{~min} /$ day. Pulsed ultrasound $(1 \mathrm{MHz})$ at duty cycles of $20 \%$ and $50 \%$ was used in this study. The results are as follows: hABMSCs exposed at duty cycles of 20 and $50 \%$ had similar cell viability, which was higher than that of control. The mineralized nodule formation was markedly increased after LIPUS treatment than that of control group. Gene expression indicated that LIPUS treatment had a positive influence on the expression of mRNA for ALP and Col-I. Our study demonstrated that hABMSCs undergoing LIPUS could be positively influenced toward osteogenic differentiation. Osteoinduction of osteocalcin showed more intense observations for the LIPUS induction groups compared to the control. Signal transduction via LIPUS ultimately could enhance adhesion molecules, and then generate osteogenesis. These results suggest that LIPUS treatment could affect the cell viability and osteogenic differentiation of hABMSCs, as well as be part of effective treatment methods for clinical applications.

\section{Conflict of Interests}

The authors have no conflicting financial or other interests.

\section{Acknowledgment}

This research was supported by Technology Development Program for IPET (Korea Institute of Planning and Evaluation for Technology in Food, Agriculture, Forestry and Fisheries), Republic of Korea (312031-3).

\section{References}

[1] M. J. Buckley, A. J. Banes, L. G. Levin et al., "Osteoblasts increase their rate of division and align in response to cyclic, mechanical tension in vitro," Bone and Mineral, vol. 4, no. 3, pp. 225-236, 1988.

[2] I. Binderman, U. Zor, A. M. Kaye, Z. Shimshoni, A. Harell, and D. Somjen, "The transduction of mechanical force into biochemical events in bone cells may involve activation of phospholipase A2," Calcified Tissue International, vol. 42, no. 4, pp. 261-266, 1988.

[3] J. Rubin, D. Biskobing, X. Fan, C. Rubin, K. McLeod, and W. R. Taylor, "Pressure regulates osteoclast formation and MCSF expression in marrow culture," Journal of Cellular Physiology, vol. 170, no. 1, pp. 81-87, 1997.

[4] J. D. Heckman, J. P. Ryaby, J. McCabe, J. J. Frey, and R. F. Kilcoyne, "Acceleration of tibial fracture-healing by noninvasive, low-intensity pulsed ultrasound," Journal of Bone and Joint Surgery-Series A, vol. 76, no. 1, pp. 26-34, 1994.

[5] S. D. Cook, J. R. Ryaby, J. McCabe, J. J. Frey, J. D. Heckman, and T. K. Kristiansen, "Acceleration of tibia and distal radius fracture healing in patients who smoke," Clinical Orthopaedics and Related Research, no. 337, pp. 198-207, 1997.

[6] A. Shimazaki, K. Inui, Y. Azuma, N. Nishimura, and Y. Yamano, "Low-intensity pulsed ultrasound accelerates bone maturation in distraction osteogenesis in rabbits," Journal of Bone and Joint Surgery-Series B, vol. 82, no. 7, pp. 1077-1082, 2000.
[7] E. Mayr, V. Frankel, and A. Rüter, "Ultrasound-an alternative healing method for nonunions?" Archives of Orthopaedic and Trauma Surgery, vol. 120, no. 1-2, pp. 1-8, 2000.

[8] H. El-Mowafi and M. Mohsen, "The effect of low-intensity pulsed ultrasound on callus maturation in tibial distraction osteogenesis," International Orthopaedics, vol. 29, no. 2, pp. 121124, 2005.

[9] J. Schortinghuis, A. L. J. J. Bronckers, B. Stegenga, G. M. Raghoebar, and L. G. M. de Bont, "Ultrasound to stimulate early bone formation in a distraction gap: a double blind randomised clinical pilot trial in the edentulous mandible," Archives of Oral Biology, vol. 50, no. 4, pp. 411-420, 2005.

[10] J. Wolff, The Law of Bone Remodeling. Maquet P, Furlong R, Translators, Springer, New York, NY, USA, 1986.

[11] T. S. Gross, J. L. Edwards, K. J. Mcleod, and C. T. Rubin, "Strain gradients correlate with sites of periosteal bone formation," Journal of Bone and Mineral Research, vol. 12, no. 6, pp. 982988, 1997.

[12] C. Rubin, M. Bolander, J. P. Ryaby, and M. Hadjiargyrou, "The use of low-intensity ultrasound to accelerate the healing of fractures," Journal of Bone and Joint Surgery-Series A, vol. 83, no. 2, pp. 259-270, 2001.

[13] E. T. Lee, K. T. Lim, J. H. Kim et al., "Effects of low intensity ultrasound stimulation on the proliferation of alveolar bone marrow stem cell," Tissue Engineering and Regenerative Medicine, vol. 5, no. 4, pp. 572-580, 2008.

[14] A. Khanna, R. T. C. Nelmes, N. Gougoulias, N. Maffulli, and J. Gray, "The effects of LIPUS on soft-tissue healing: a review of literature," British Medical Bulletin, vol. 89, no. 1, pp. 169-182, 2009.

[15] W. H. S. Chang, J. S. Sun, S. P. Chang, and J. C. Lin, "Study of thermal effects of ultrasound stimulation on fracture healing," Bioelectromagnetics, vol. 24, no. 4, pp. 253-263, 2002.

[16] J. Wu and G. Du, “Temperature elevation in tissues generated by finite-amplitude tone bursts of ultrasound," Journal of the Acoustical Society of America, vol. 88, no. 3, pp. 1562-1577, 1990.

[17] H. G. Welgus, J. J. Jeffrey, and A. Z. Eisen, "Human skin fibroblast collagenase. Assessment of activation energy and deuterium isotope effect with collagenous substrates," Journal of Biological Chemistry, vol. 256, no. 18, pp. 9516-9521, 1981.

[18] C. Dee, J. Shim, C. Rubin, and K. McLeod, "Modulation of osteoblast proliferation and differentiation by subtle alterations in temperature," Transactions of the Orthopedic Research Society, vol. 21, article 341, 1996.

[19] T. Kamakura, K. Matsuda, Y. Kumamoto, and M. A. Breazeale, "Acoustic streaming induced in focused Gaussian beams," Journal of the Acoustical Society of America, vol. 97, no. 5 I, pp. 2740-2746, 1995.

[20] I. Binderman, U. Zor, A. M. Kaye, Z. Shimshoni, A. Harell, and D. Somjen, "The transduction of mechanical force into biochemical events in bone cells may involve activation of phospholipase A2," Calcified Tissue International, vol. 42, no. 4, pp. 261-266, 1988.

[21] M. J. Buckley, A. J. Banes, L. G. Levin et al., "Osteoblasts increase their rate of division and align in response to cyclic, mechanical tension in vitro," Bone and Mineral, vol. 4, no. 3, pp. 225-236, 1988.

[22] J. Rubin, D. Biskobing, X. Fan, C. Rubin, K. McLeod, and W. R. Taylor, "Pressure regulates osteoclast formation and MCSF expression in marrow culture," Journal of Cellular Physiology, vol. 170, no. 1, pp. 81-87, 1997. 
[23] M. Dyson, "Non-thermal cellular effects of ultrasound," British Journal of Cancer, vol. 45, no. 5, pp. 165-171, 1982.

[24] A. J. Mortimer and M. Dyson, "The effect of therapeutic ultrasound on calcium uptake in fibroblasts," Ultrasound in Medicine and Biology, vol. 14, no. 6, pp. 499-506, 1988.

[25] M. A. Dinno, M. Dyson, S. R. Young, A. J. Mortimer, J. Hart, and L. A. Crum, "The significance of membrane changes in the safe and effective use of therapeutic and diagnostic ultrasound," Physics in Medicine and Biology, vol. 34, no. 11, pp. 1543-1552, 1989.

[26] N. Wang, J. P. Butler, and D. E. Ingber, "Mechanotransduction across the cell surface and through the cytoskeleton," Science, vol. 260, no. 5111, pp. 1124-1127, 1993.

[27] J. Parvizi, C.-C. Wu, D. G. Lewallen, J. F. Greenleaf, and M. E. Bolander, "Low-intensity ultrasound stimulates proteoglycan synthesis in rat chondrocytes by increasing aggrecan gene expression," Journal of Orthopaedic Research, vol. 17, no. 4, pp. 488-494, 1999.

[28] J. Parvizi, V. Parpura, J. F. Greenleaf, and M. E. Bolander, "Calcium signaling is required for ultrasound-stimulated aggrecan synthesis by rat chondrocytes," Journal of Orthopaedic Research, vol. 20, no. 1, pp. 51-57, 2002.

[29] S. Takikawa, N. Matsui, T. Kokubu et al., "Low-intensity pulsed ultrasound initiates bone healing in rat nonunion fracture model," Journal of Ultrasound in Medicine, vol. 20, no. 3, pp. 197205, 2001.

[30] D. B. Jones, H. Nolte, J.-G. Scholubbers, E. Turner, and D. Veltel, "Biochemical signal transduction of mechanical strain in osteoblast-like cells," Biomaterials, vol. 12, no. 2, pp. 101-110, 1991.

[31] D. Somjen, I. Binderman, E. Berger, and A. Harell, "Bone remodelling induced by physical stress is prostaglandin E2 mediated," Biochimica et Biophysica Acta, vol. 627, no. 1, pp. 91100,1980 .

[32] I. Binderman, Z. Shimshoni, and D. Somjen, "Biochemical pathways involved in the translation of physical stimulus into biological message," Calcified Tissue International, vol. 36, no. 1, pp. S82-S85, 1984.

[33] W. Harvey, M. Dyson, J. B. Pond, and R. Grahame, "The stimulation of protein synthesis in human fibroblasts by therapeutic ultrasound," Rheumatology and Rehabilitation, vol. 14, no. 4, article 237, 1975.

[34] D. F. Webster, J. B. Pond, M. Dyson, and W. Harvey, "The role of cavitation in the in vitro stimulation of protein synthesis in human fibroblasts by ultrasound," Ultrasound in Medicine and Biology, vol. 4, no. 4, pp. 343-351, 1978.

[35] D. F. Webster, W. Harvey, M. Dyson, and J. B. Pond, “The role of ultrasound-induced cavitation in the 'in vitro' stimulation of collagen synthesis in human fibroblasts," Ultrasonics, vol. 18, no. 1, pp. 33-37, 1980.

[36] K.-H. Yang, J. Parvizi, S.-J. Wang et al., "Exposure to lowintensity ultrasound increases aggrecan gene expression in a rat femur fracture model," Journal of Orthopaedic Research, vol. 14, no. 5, pp. 802-809, 1996.

[37] F.-S. Wang, Y.-R. Kuo, C.-J. Wang et al., "Nitric oxide mediates ultrasound-induced hypoxia-inducible factor- $1 \alpha$ activation and vascular endothelial growth factor-A expression in human osteoblasts," Bone, vol. 35, no. 1, pp. 114-123, 2004.

[38] R. Adell, B. Eriksson, U. Lekholm, P. I. Brånemark, and T. Jemt, "Long-term follow-up study of osseointegrated implants in the treatment of totally edentulous jaws," The International Journal of Oral \& Maxillofacial Implants, vol. 5, no. 4, pp. 347-359, 1990.
[39] R. Gapski, H.-L. Wang, P. Mascarenhas, and N. P. Lang, "Critical review of immediate implant loading," Clinical Oral Implants Research, vol. 14, no. 5, pp. 515-527, 2003.

[40] R.-S. Yang, W.-L. Lin, Y.-Z. Chen et al., "Regulation by ultrasound treatment on the integrin expression and differentiation of osteoblasts," Bone, vol. 36, no. 2, pp. 276-283, 2005.

[41] J. G.-R. Li, W. H.-S. Chang, J. C.-A. Lin, and J.-S. Sun, "Optimum intensities of ultrasound for PGE2 secretion and growth of osteoblasts," Ultrasound in Medicine and Biology, vol. 28, no. 5, pp. 683-690, 2002.

[42] T. Kokubu, N. Matsui, H. Fujioka, M. Tsunoda, and K. Mizuno, "Low intensity pulsed ultrasound exposure increases prostaglandin E2 production via the induction of cyclooxygenase-2 mRNA in mouse osteoblasts," Biochemical and Biophysical Research Communications, vol. 256, no. 2, pp. 284-287, 1999.

[43] P. Reher, M. Harris, M. Whiteman, H. K. Hai, and S. Meghji, "Ultrasound stimulates nitric oxide and prostaglandin E2 production by human osteoblasts," Bone, vol. 31, no. 1, pp. 236-241, 2002.

[44] D. Chikazu, K. Tomizuka, T. Ogasawara et al., "Cyclooxygenase2 activity is essential for the osseointegration of dental implants," International Journal of Oral and Maxillofacial Surgery, vol. 36, no. 5, pp. 441-446, 2007.

[45] K. Lim, J. Hexiu, J. Kim et al., "Effects of electromagnetic fields on osteogenesis of human alveolar bone-derived mesenchymal stem cells," BioMed Research International, vol. 2013, Article ID 296019, 14 pages, 2013.

[46] M. R. Hausman, M. B. Schaffler, and R. J. Majeska, "Prevention of fracture healing in rats by an inhibitor of angiogenesis," Bone, vol. 29, no. 6, pp. 560-564, 2001.

[47] L. Li, Z. Zhu, C. Huang, and W. Chen, "Ultrasound: a potential technique to improve osseointegration of dental implants," Medical Hypotheses, vol. 71, no. 4, pp. 568-571, 2008. 


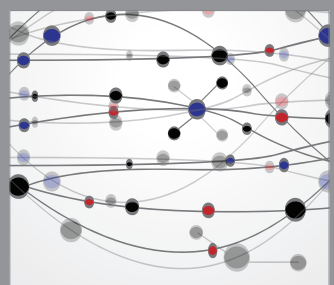

The Scientific World Journal
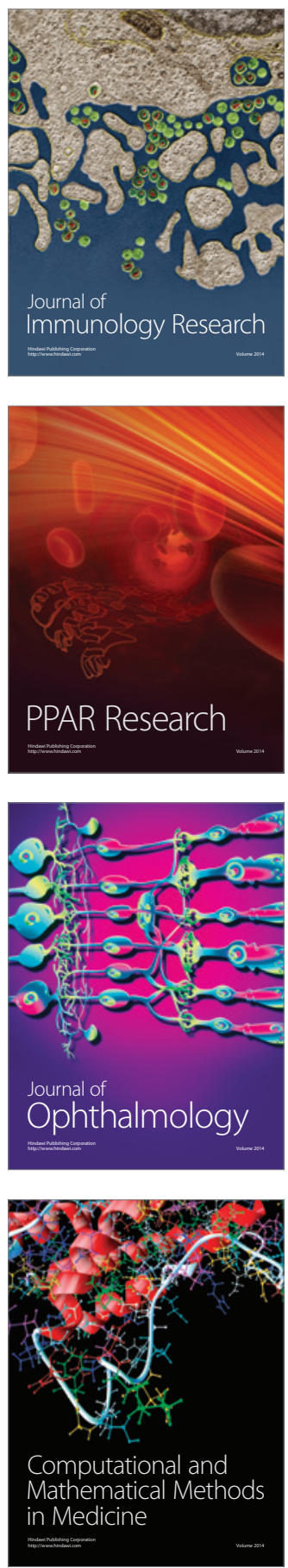

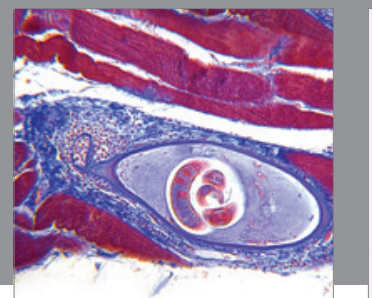

Gastroenterology

Research and Practice
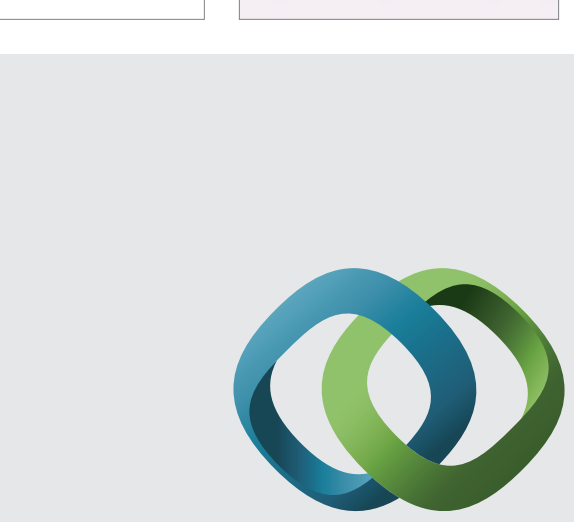

\section{Hindawi}

Submit your manuscripts at

http://www.hindawi.com
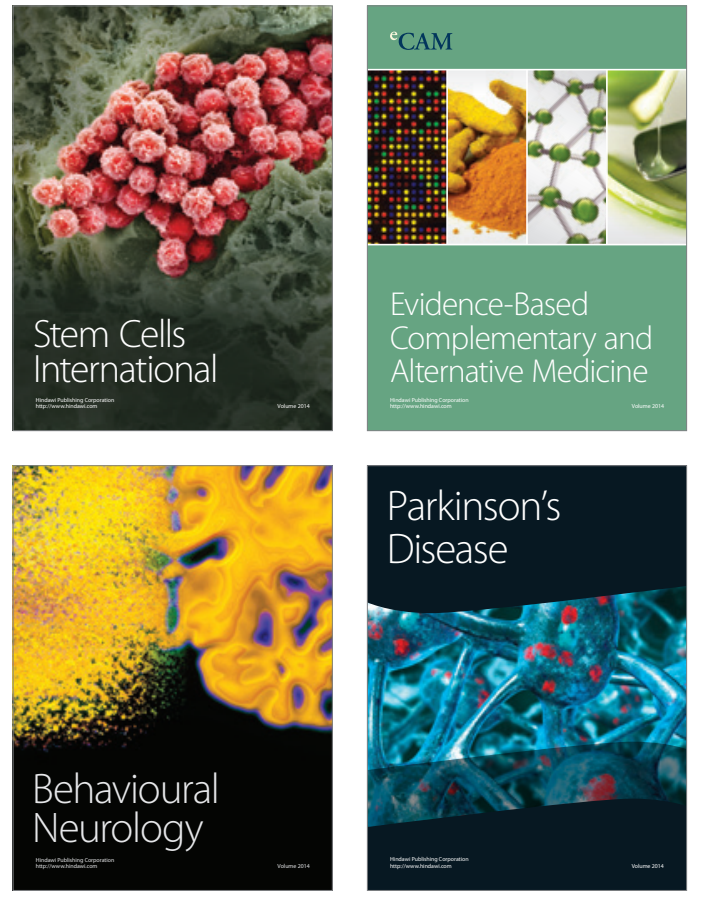
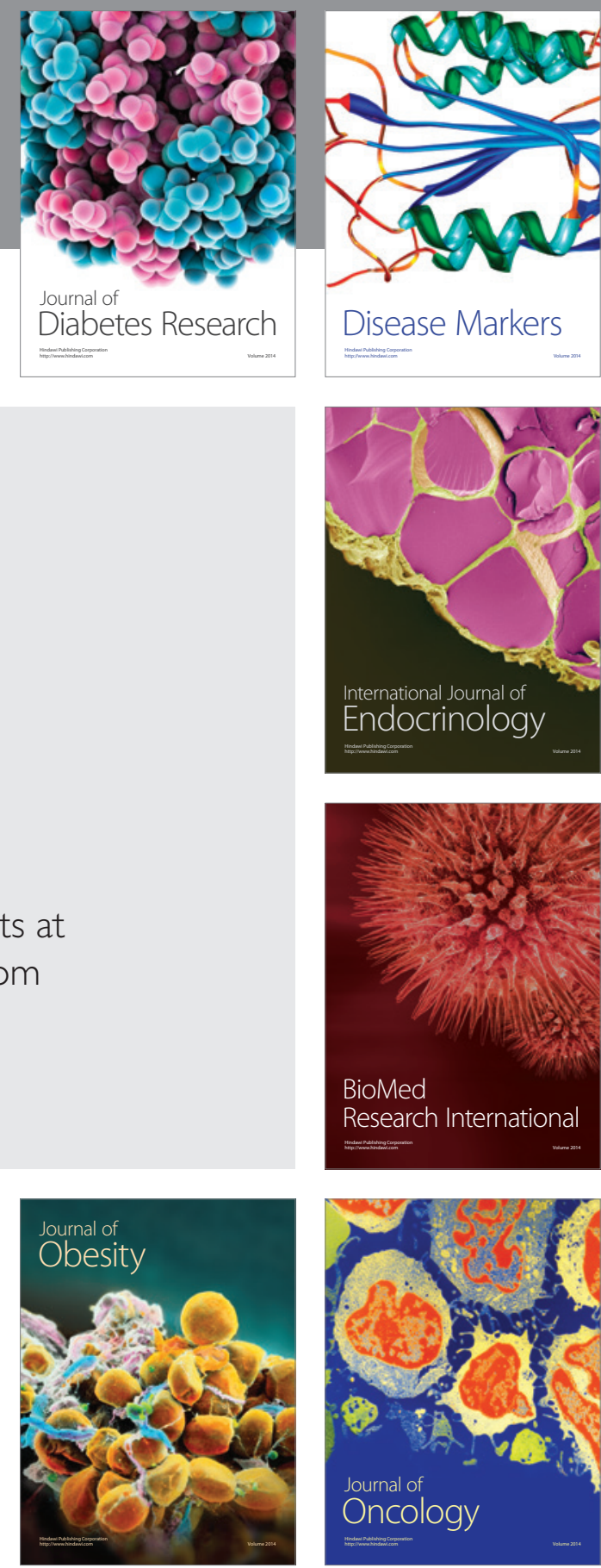

Disease Markers
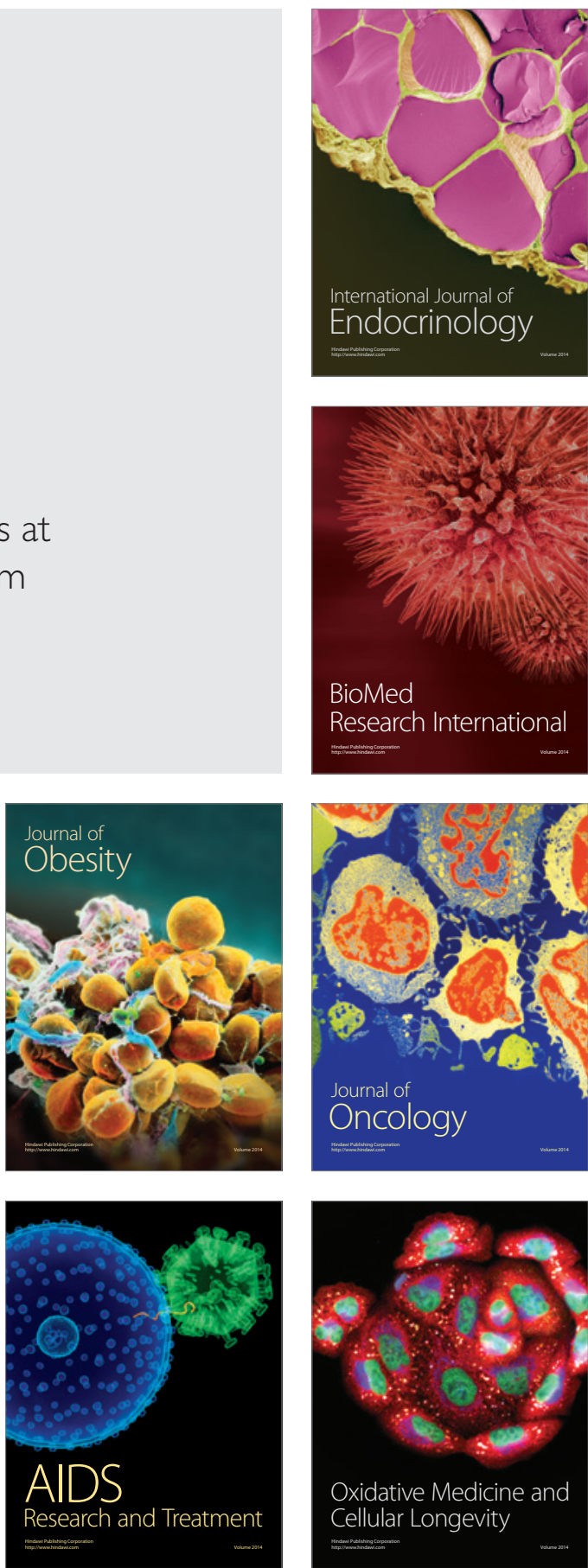